University of Wollongong

Research Online

Faculty of Engineering and Information

Faculty of Engineering and Information

Sciences - Papers: Part A

Sciences

$1-1-2016$

Application of artificial neural network coupled with genetic algorithm and simulated annealing to solve groundwater inflow problem to an advancing open pit mine

\author{
Saeed Bahrami \\ University of Tehran \\ Faramarz Doulati Ardejani \\ University of Tehran \\ Ernest Baafi \\ University of Wollongong, ebaafi@uow.edu.au
}

Follow this and additional works at: https://ro.uow.edu.au/eispapers

Part of the Engineering Commons, and the Science and Technology Studies Commons

Research Online is the open access institutional repository for the University of Wollongong. For further information contact the UOW Library: research-pubs@uow.edu.au 


\title{
Application of artificial neural network coupled with genetic algorithm and simulated annealing to solve groundwater inflow problem to an advancing open pit mine
}

\author{
Abstract \\ In this study, hybrid models are designed to predict groundwater inflow to an advancing open pit mine and \\ the hydraulic head $(\mathrm{HH})$ in observation wells at different distances from the centre of the pit during its \\ advance. Hybrid methods coupling artificial neural network (ANN) with genetic algorithm (GA) methods \\ (ANN-GA), and simulated annealing (SA) methods (ANN-SA), were utilised. Ratios of depth of pit \\ penetration in aquifer to aquifer thickness, pit bottom radius to its top radius, inverse of pit advance time \\ and the $\mathrm{HH}$ in the observation wells to the distance of observation wells from the centre of the pit were \\ used as inputs to the networks. To achieve the objective two hybrid models consisting of ANN-GA and \\ ANN-SA with 4-5-3-1 arrangement were designed. In addition, by switching the last argument of the input \\ layer with the argument of the output layer of two earlier models, two new models were developed to \\ predict the $\mathrm{HH}$ in the observation wells for the period of the mining process. The accuracy and reliability \\ of models are verified by field data, results of a numerical finite element model using SEEP/W, outputs of \\ simple ANNs and some well-known analytical solutions. Predicted results obtained by the hybrid methods \\ are closer to the field data compared to the outputs of analytical and simple ANN models. Results show \\ that despite the use of fewer and simpler parameters by the hybrid models, the ANN-GA and to some \\ extent the ANN-SA have the ability to compete with the numerical models. \\ Disciplines \\ Engineering | Science and Technology Studies \\ Publication Details \\ Bahrami, S., Doulati Ardejani, F. \& Baafi, E. (2016). Application of artificial neural network coupled with \\ genetic algorithm and simulated annealing to solve groundwater inflow problem to an advancing open pit \\ mine. Journal of Hydrology, 536 471-484.
}

This journal article is available at Research Online: https://ro.uow.edu.au/eispapers/5276 


\title{
Application of artificial neural network coupled with genetic algorithm and simulated
}

\section{annealing to solve groundwater inflow problem to an advancing open pit mine}

\author{
Saeed Bahrami ${ }^{\mathrm{a}, \mathrm{b}}$, Faramarz Doulati Ardejani ${ }^{\mathrm{a}, \mathrm{b}}$, Ernest Baafi $^{\mathrm{c}}$ \\ a. School of Mining, College of Engineering, University of Tehran, Tehran, Iran \\ b. Mine Environment and Hydrogeology Research Laboratory, University of Tehran, Tehran, Iran \\ c. School of Civil, Mining and Environmental Engineering, University of Wollongong, Wollongong, NSW 2522, Australia
}

Corresponding Author: Faramarz Doulati Ardejani; (fdoulati@ut.ac.ir); Tel: +9809121096153.

\begin{abstract}
In this study, hybrid models are designed to predict groundwater inflow to an advancing open pit mine and the hydraulic head $(\mathrm{HH})$ in observation wells at different distances from the centre of the pit during its advance. Hybrid methods coupling artificial neural network (ANN) with genetic algorithm (GA) methods (ANN-GA), and simulated annealing (SA) methods (ANN-SA), were utilised. Ratios of depth of pit penetration in aquifer to aquifer thickness, pit bottom radius to its top radius, inverse of pit advance time and the $\mathrm{HH}$ in the observation wells to the distance of observation wells from the centre of the pit were used as inputs to the networks. To achieve the objective two hybrid models consisting of ANN-GA and ANN-SA with 4-5-3-1 arrangement were designed. In addition, by switching the last argument of the input layer with the argument of the output layer of two earlier models, two new models were developed to predict the HH in the observation wells for the period of the mining process. The accuracy and reliability of models are verified by field data, results of a numerical finite element model using SEEP/W, outputs of simple ANNs and some well-known analytical solutions. Predicted results obtained by the hybrid methods are closer to the field data compared to the outputs of analytical and simple ANN models. Results show that despite the use of fewer and simpler parameters by the hybrid models, the ANN-GA and to some extent the ANN-SA have the ability to compete with the numerical models.
\end{abstract}

Keywords: Mine hydrogeology, Groundwater inflow, Genetic algorithm, Simulated annealing, Artificial neural networks, Numerical model

\section{Introduction}

Groundwater is a natural resource, which can have negative effects on mining operation (Brawner, 1986). In mines where excavation is carried out below the water table, water flows from the surrounding strata towards the mining works. In particular, in the case of a confined aquifer, as the overburden materials and the mineral deposit are extracted during the mining operation, the impervious bed(s) may break and water under high-pressure may flow into the mining excavation (Bahrami et al., 2014). Investigations have revealed that the resulting unexpected inflows in large quantities may impede 
production, delay the project and may cause many safety and environmental problems (Singh and Atkins, 1985a, b). Undesirable effects of this may include:

- loss of access to all or part of the mine working area

- greater use of explosives

- increased explosive failures resulting from wet blast holes, or the need to use special explosives

- increased wear to equipment and tyres

- inefficient loading and hauling

- unsafe working conditions (Morton and Van Mekerk, 1993).

Furthermore, groundwater inflow can have a harmful effect on pit slope stability. Hence, it is necessary to design an effective dewatering system to defeat these problems and simulation of groundwater inflow will greatly assist in this design work.

Further problems can follow because dewatering can place considerable hydrological stress on the regional groundwater system by creating an extensive and prolonged cone of depression, regional groundwater table lowering, overlapping cones of depression, land subsidence, and water quality deterioration, problems which can endanger mine productivity and even human life (Keqiang et al., 2006). All of these problems are related to changes in hydraulic head (Morton and Van Mekerk, 1993) so modelling the hydraulic head during pit advance can provide valuable information for designing an appropriate dewatering scheme.

Many analytical solutions have been used to estimate groundwater inflow into mining excavations (e.g. Hofedank and Engineers, 1979; Lewis, 1999; Marinelli and Niccoli, 2000; McWhorter, 1981; Singh and Atkins, 1985a, b; Singh et al., 1985; Singh and Reed, 1987; Singh and Atkins, 1984; Vandersluis et al., 1995) but analytical models are based on some assumptions and specific boundary conditions that limit their applicability in different mining situations. For example, most analytical solutions do not directly account for inflow through the pit bottom (Hanna et al., 1994) and they cannot simulate hydraulic head and saturated/unsaturated flow conditions in a confined aquifer (Doulati Ardejani et al., 2003a). Hence, analytical solutions are not appropriate for all hydrogeological situations.

Numerical models are routinely used for simulation of the groundwater flow in a complex aquifer system, the finite element method incorporating the Galerkin approach (Gray and Pinder, 1974) being recognised as a strong and powerful numerical technique for this purpose (Rabbani and Warner, 1994). Several numerical models have been developed to predict the groundwater inflow to open pit mines and to predict the hydraulic head in observation wells at different distances from the centre of the pit (e.g. Aryafar et al., 2009; Bahrami et al., 2014; Crowe et al., 2004; Doulati Ardejani et al., 2003a; Hernández et al., 2012; Singh et al., 2012).

Bahrami et al. (2014) presented a two-dimensional (2D) numerical finite element model using SEEP/W (Geo-slope International Limitd, 2012) software to predict the groundwater inflow to an open pit mine, and modeled the hydraulic head 
in observation wells at different distances from the centre of the pit, for the period of the mining process. The accuracy and reliability of this model results were verified by field data and the results obtained by analytical solutions.

Doulati Ardejani et al. (2003a) presented a 2D numerical finite element model using SEEP/W software to predict groundwater inflow to surface mining excavations and to calculate the height of the seepage face in and around the pits. They simulated saturated/unsaturated flow conditions, taking into account the hydraulic conductivities and the water content as a function of pore water pressure. The simulation results were compared to those from analytical solutions and other existing numerical codes developed for pit inflow prediction but the application of the model in a real mine was not evaluated.

Crowe et al. (2004) developed a numerical model to simulate groundwater-wetland interactions and contaminant transport. The model calculates transient hydraulic head and a transient free surface in a 2D, heterogeneous domain, with variable and transient boundary conditions. It includes infiltration, evapotranspiration and surface water flow together with the water and contaminant fluxes across the aquifer-wetland interface.

Hernández et al. (2012) developed a physically-based numerical model that includes new approaches for a finite element solution to the steady-transient problems of the joint surface-groundwater flows of a particular region using a Geographic Information Systems to store, characterize, manage and take decisions on all the simulated conditions.

Aryafar et al. (2009) applied SEEP/W software as a simulation tool to predict groundwater inflow from an infinite confined aquifer into the Sangan open pit mine. The inflow simulation was first evaluated and verified by comparing the output from the model with results obtained from Theis, Cooper-Jacob and Jacob-Lohman analytical solutions. The model was then used to predict groundwater inflow into the Sangan open pit mine during its advance. It was found that the analytical Jacob-Lohman solution and the numerical model present an approximately similar trend of inflow rate as a function of time. Although the model describes well the inflow problem related to a confined aquifer, a comparison between the predicted inflow and the real inflow was not presented.

Singh et al. (2012) investigated the hydrogeological problems relating to the Thar lignite field in Sindh, Pakistan. They described the proposed mine dewatering system to facilitate depressurising of the rock mass surrounding the mining excavations. A SEEP/W finite element model was used to predict groundwater inflow to the surface mining excavation during its advance. A sensitivity analysis was carried out to evaluate various factors affecting groundwater inflow. It was concluded that the model is very sensitive to permeability of the aquifer.

Numerical methods have been also used by the other researchers to simulate mine water problems (e.g. Azrag et al., 1998; Davis and Zabolotney, 1996; Dong et al., 2012; Naugle and Atkinson, 1993; Rogowski and Weinrich, 1981).

Although numerical methods have been widely used for groundwater flow modelling and mine water related problems, these models require many parameters including hydraulic conductivity of the aquifer, transmissivity, pre-dewatering initial hydraulic head, rainfall data, saturated thickness of the aquifer, specific storage, porosity and other specific initial and boundary conditions. Determining all of these highly nonlinear characteristics is very difficult and requires a lot of time and 
cost. In addition, the number of factors required for developing a model can increase the uncertainty of its final results by accumulation of the miscalculations in the factors.

Approximation models such as artificial neural networks (ANNs) provide a powerful and reliable alternative with fewer required inputs to predict the nonlinear behaviour of groundwater inflow to open pit mines and changes in hydraulic head in the vicinity of the mine during pit advance. An ANN is an empirical modelling tool that is based on the behaviour of biological neural structures (Doulati Ardejani et al., 2013; Yao et al., 2005) and the use of such networks is rapidly increasing, especially in process modelling, simulation and predictions (Banerjee et al., 2011; Doulati Ardejani et al., 2013; Khalil et al., 2011; Sadeghiamirshahidi and Ardejani, 2013; Yoon et al., 2011).

Doulati Ardejani et al. (2013) presented a neural network model to predict the groundwater rebound process after cessation of dewatering at a restored open cut coal site in the East Midlands area of the UK. Time (days after dewatering), water table levels in the aquifer and the backfilled site, hydraulic conductivity of the aquifer and backfilled site, and precipitation were used as inputs. The output of the network was the water table height (residual drawdown). A feedforward artificial neural network incorporating batch gradient descent with a momentum-learning algorithm and 6-1-6-1 arrangement was used to achieve this goal.

Banerjee et al. (2011) developed an artificial neural network (ANN) to estimate groundwater salinity in island aquifers. A Feed-forward ANN model with quick propagation as training algorithm has been used to forecast the salinity under varied pumping rates.

Yoon et al. (2011) presented two nonlinear time-series models for predicting groundwater level (GWL) fluctuations using artificial neural networks (ANNs) and support vector machines (SVMs). The models were applied to GWL prediction of two wells at a coastal aquifer in Korea.

Three models have been developed by Khalil et al. (2011), for the estimation of water quality mean values at ungauged sites. The first model is based on ANNs, the second model is based on ensemble ANN (EANN) and the third one is based on canonical correlation analysis (CCA) and EANN.

Sadeghiamirshahidi and Ardejani (2013) presented a feed-forward multi-layer ANN with back-propagation learning algorithm, with 4-7-4-1 arrangement to predict pyrite oxidation process in the spoils of the Anjir Tangeh coal washing plant, northern Iran. The spoil depth, annual precipitation, effective diffusion coefficient of oxygen transport and initial amount of pyrite in the spoil particles were the inputs and the fraction of pyrite remaining in the spoil was the output of the model.

The performance of an artificial neural network depends upon the selection of proper weight connections and network topology during network training. Due to the complex nature of neural network training, even simple functions result in very complex error surfaces. Since the nature of neural network learning algorithms is local convergence, it can be demonstrated that solutions are highly dependent upon the initial random drawing of connection weights. If these initial weights are located on a local grade, which is probable, the learning algorithm will likely become trapped in a local solution that may or may not be the global solution (Zanchettin and Ludermir, 2007). Global search techniques are known to more 
consistently obtain the optimal solution (Sexton et al., 1999). Recently GA and SA have been combined with neural methods to avoid drawbacks of local minimization methods. Many other global minimization methods are suitable for that purpose, although they are used rather rarely in this context (Duch and Korczak, 1998; Bhattacharjya and Datta, 2009; Yeh, 2015; Sreekanth and Datta, 2015). The coupled ANN-GA and ANN-SA algorithms have a great potential to handle problems such as optimization in complicated nonlinear systems. These methods have been used by many researchers (e.g. Alavi and Gandomi, 2011; Hao et al., 2004; Kana et al., 2012; Yeh, 2015).

Yeh (2015) reviewed the various optimization approaches, such as GA and gradient-based methods that have been used for solving the groundwater planning and management programs. The author explained the idea that, a key advantage of using the GA method is to solve non-linear optimization problems. In order to enhance the efficiency of the GA method, it may be coupled with the gradient-based optimizer methods.

Alavi and Gandomi (2011) developed new models to predict the peak time-domain characteristics of strong groundmotions utilising a hybrid method (ANNs-SA). The principal groundmotion parameters formulated were peak ground acceleration (PGA), peak ground velocity (PGV) and peak ground displacement (PGD). The proposed models relate PGA, PGV and PGD to earthquake magnitude, earthquake source to site distance, average shear-wave velocity and faulting mechanisms.

Despite the remarkable prediction capabilities of ANNs methods and especially hybrid models, such as ANNs-GA and ANNs-SA, there have not yet been any scientific efforts directed at applying them to model groundwater inflow to mines.

In this study, hybrid models (ANNs-GA and ANNs-SA) are utilised to predict groundwater inflow to an open pit mine and model the hydraulic head at different distances from the centre of the pit during mining operations. For this purpose, MATLAB software was used. The accuracy of these hybrid models is verified by field data, results of a $2 \mathrm{D}$ axisymmetric finite element model using the SEEP/W package, outputs of a feed-forward artificial neural network with back-propagation learning algorithm and some of the famous analytical solution results.

It is noted that the field data include the quantity of groundwater inflow from a confined aquifer to an open pit mine (Goushfil pit, Central Iran) and the hydraulic heads at two observation wells around the pit during its advance over 30 weeks (Esfahan province environmental office, 2013). In addition, the hydrodynamic coefficients of the aquifer were calculated using a pump out test conducted within 22 hours. The modelling methods described in this paper can be used to develop an effective dewatering program.

\section{Study Area and Data Collection}

\subsection{Geographical Situation and the Climate}

Geological investigations have revealed that several $\mathrm{Zn}-\mathrm{Pb}$ deposits are situated in the Irankuh district. They include the Goushfil pit (sulphide ore), the Kolahdarvazeh pit (non-sulphide ore) and the Tappeh-Sorkh pit, located in the Irankuh 
Mountain Range, $20 \mathrm{~km}$ south of Esfahan and $1 \mathrm{~km}$ north-east of Abnil in West-Central Iran. The elevation of the mines is approximately $1700 \mathrm{~m}$ above sea level. The mineable ore reserve of these mines is approximately 8 million tones with $7 \%$ zinc and $2.5 \%$ lead. Mining operations in the Goushfil mine started in 1962.

The study area is characterised by a warm climate with an annual relative humidity of 30\% (BAMA Mining Company, 2003; Esfahan province environmental office, 2013). The average annual precipitation at the site varies between 100 and $150 \mathrm{~mm}$. Fig. 1 shows the location of the study area and a schematic view of the Goushfil open pit mine, pumping well and observation wells. Observation wells 1 and 2 are located at 1250 and $1750 \mathrm{~m}$ distance from the centre of the pit, respectively. 


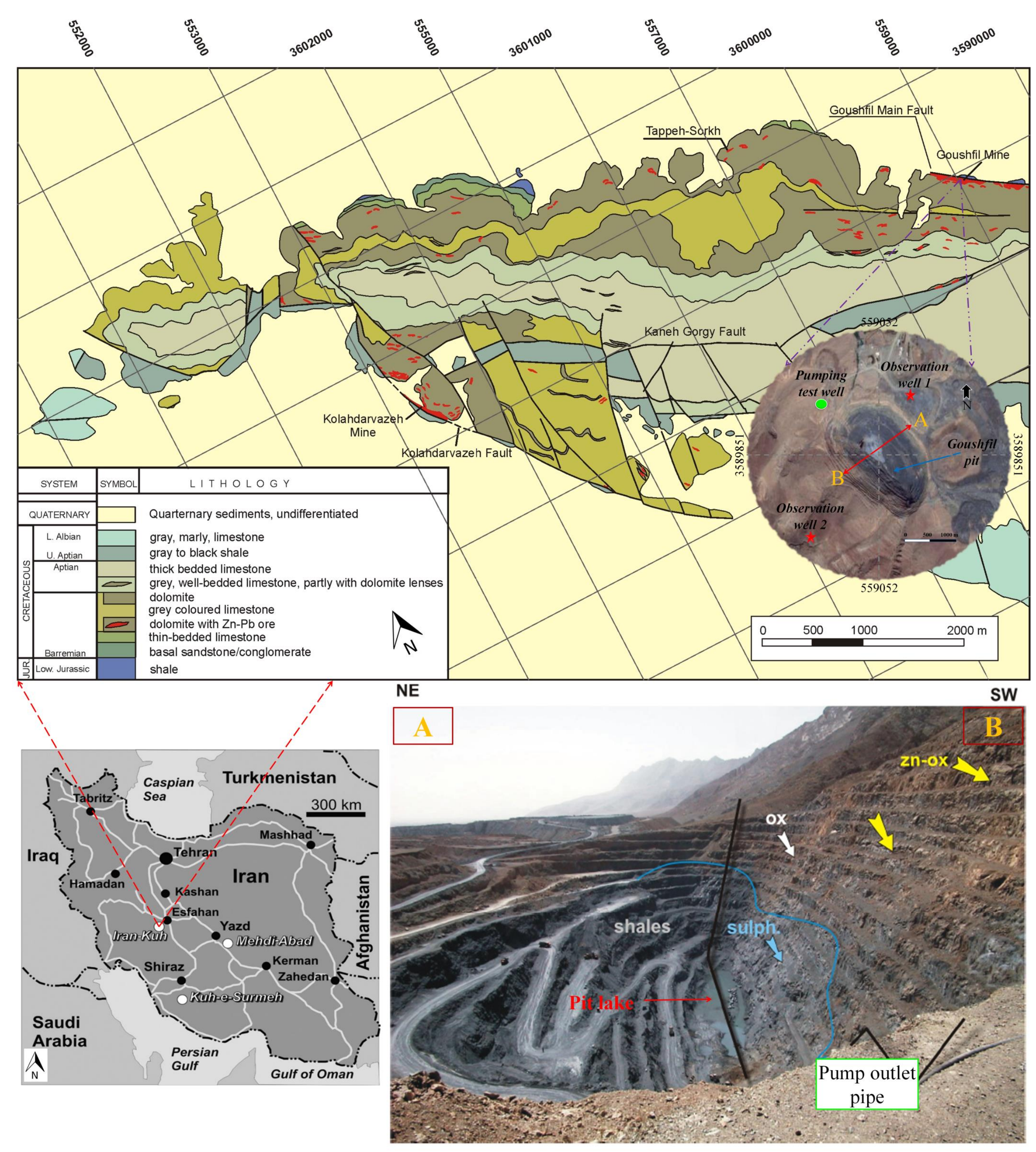

Fig. 1. The location of the study area and a schematic view of the open pit, pumping well and observation wells (Modified after Reichert, 2007). 


\subsection{Geology}

The main zone of the mine is covered with carbonate sediments which are located on lower Jurrassic sediments unconformably and consist of continuous Cretaceous age deposits. The total thickness of these rocks is above $800 \mathrm{~m}$ which comprise limestone and dolomite with lesser amounts of shale and marl. The carbonate sediments are identified as a source rock for Goushfil mine deposit.

\subsection{Hydrogeological Investigation and Precipitation}

Investigations (BAMA Mining Company, 2003; Reichert, 2007) showed a fully saturated confined aquifer with an average thickness of $35 \mathrm{~m}$ in the Irankuh district in the dolomite rocks extending toward the Goushfil mine throughout the study area. It is an artesian aquifer type with an $80 \mathrm{~m}$ initial head and a porous medium flow domain is dominant. The hydraulic conductivity and storage coefficient of the confined aquifer were $4 \times 10^{-5} \mathrm{~m} / \mathrm{s}$ and 0.1 respectively.

\subsection{Pit Geometry}

Information about the ore body comprising thickness, dip, depth, lateral extension and the proposed mining boundaries define the pit geometry (Singh et al., 1985). Topmost and bottommost benches of the study pit were at elevations $1680 \mathrm{~m}$ (level of the upper bench where zone $\mathrm{Zn}-\mathrm{OX}$ exists) and $1595 \mathrm{~m}$ (at the level of the pit lake bottom) and the periphery extended approximately $1600 \mathrm{~m} \mathrm{NW-SE}$, perpendicular to the section AB, and $1350 \mathrm{~m} \mathrm{NE}-\mathrm{SW}$, in the section AB (Fig. 1). The confined aquifer upper layer is located at $1625 \mathrm{~m}$ above sea level. The parameters considered in the open pit design were bench height of $10 \mathrm{~m}$, individual bench slope of $70^{\circ}$, overall pit slope of $45^{\circ}$. In the final stage of mine development, the pit had penetrated $30 \mathrm{~m}$ into the confined aquifer (BAMA Mining Company, 2003).

\subsection{Measuring Field Data}

Field data which were measured in this study included rate of groundwater inflow from the confined aquifer to the Goushfil open pit mine, hydraulic heads at two observation wells (observation wells 1 and 2 in Fig. 1) around the pit during its advance over thirty weeks, hydrodynamic coefficients and hydraulic heads at another observation well, $15 \mathrm{~m}$ from the pumping-test well (Fig. 1), over a 22 hour period. All of the observation wells and the pump-test well fully penetrated the confined aquifer.

The water levels were monitored at the observation wells using a tape measure equipped with a device that is designed to make a noise when it touches the water surface. To quantify the aquifer hydrodynamic parameters including transmissivity and storage coefficient, a $0.25 \mathrm{~m}$ diameter pumping-test well was drilled using a cable tool drilling method. The pit inflow rate from the confined aquifer was obtained by measuring the pump-out rate from the pit lake to maintain a constant water level equal to the height of the pit floor. In all wells, the aquifer thickness was approximately $35 \mathrm{~m}$. The hydraulic conductivity and storativity values of the aquifer, obtained from the pump-test data, were $4 \times 10^{-5} \mathrm{~m} / \mathrm{s}$ and 0.1 respectively. 
A total of 129 data sets were used for training and testing the networks for predicting the rate of groundwater inflow to the mine (102 sets for training and 27 sets for testing the networks).The data sets used for training the networks were from Esfahan province environmental office (2013).

A total of 237data sets were used for training and testing the networks to predict hydraulic head in observation wells in the vicinity of the pit during its advance (177 sets for training and 60 sets for testing the networks). The data sets used for training the networks come from previous works (Bahrami et al., 2014; Esfahan province environmental office, 2013). The 60 data sets from two distinct observation wells in this study (Fig. 1) were used for testing the networks.

\subsection{Description of Pit Progress into the Aquifer}

When the pit bottom reaches the upper layer of the confined aquifer, depth of pit penetration in aquifer is assumed zero and when it reaches the bottom layer of the aquifer, the depth of pit penetration in aquifer will be the aquifer thickness (the vertical distance between two confining layers).

A phase of pit advance is defined as the amount of penetration of pit into the aquifer. It is equal to the height of a bench $(10 \mathrm{~m})$. It should be noted that for further penetration of pit into the aquifer and creating a new bench, the existing benches are extended laterally. Each phase of the pit advance may include a number of time steps, as weeks during the inflow process. In each time step, the top base pit radius is described as radius of the pit at the uppermost confining layer of aquifer and the bottom base pit radius is the radius of pit in the bottom confining layer of aquifer.

\section{Methodology}

\subsection{Artificial Neural Networks (ANNs)}

Different types of ANNs have previously been used in hydrological modelling (e.g. Adamowski and Sun, 2010; Banerjee et al., 2011; Belayneh et al., 2014; Cannas et al., 2005; Chen and Chang, 2009; Chiang et al., 2004; Doulati Ardejani et al., 2013; Imrie et al., 2000; Ketabchi and Ataie-Ashtiani, 2015; Khalil et al., 2011; Sivakumar et al., 2002; Yoon et al., 2011). The most popular ANN model is the multi-layer perceptron (MLP) which includes a feed-forward and layered network of neurons and can provide a nonlinear mapping between the input and output.

The general relationship between input and output in an ANN model can be expressed as (Fazeli et al., 2013):

$$
y_{k}=f_{0}\left[\sum_{j} w_{k j} \cdot f_{h}\left(\sum_{i} w_{j i} x_{i}+b_{j}\right)+b_{k}\right]
$$

where, $x$ is an input vector; $w_{j i}$ denotes the connection weight from the $i$ th neuron in the input layer to the $j$ th neuron in the hidden layer; $b_{j}$ represents the threshold value or bias of $j$ th hidden neuron; $w_{k j}$ stands for the connection weight from the $j$ th neuron in the hidden layer to the $k$ th neuron in the output layer; $b_{k}$ refers to the bias of the $k$ th output neuron and $f_{h}$ and $f_{0}$ are the transfer functions for the hidden and output neuron respectively. Sigmoidal-type transfer functions and linear transfer functions are recommended for the hidden and output layer respectively (Mekanik et al., 2013). The objective is to 
find the value of the weight that minimises differences between the real output and the predicted output in the output layer in order to minimise the mean square errors (MSEs), the average squared error between the network predictions and the target outputs (Sadeghiamirshahidi and Ardejani, 2013). In order to find the optimal weight (w) and the bias (b), training or learning processes must be implemented to minimise the error (Fazeli et al., 2013).

In recent years, the literature contains details of several optimization algorithms which have been presented and extensively investigated. Most of them were based on deterministic or stochastic methods, in order to solve optimization problems with multiple objectives that conflict with each other. Some multi-objective stochastic optimizers have been developed based on local or global search methods to solve optimal design problems.

Most local optimization algorithms are gradient-based. They utilise gradient information to find the optimum solution, and such algorithms are widely used to solve a variety of optimization problems in engineering. However, these algorithms have several drawbacks in that they can only find a local optimum. In addition, they have difficulty in solving discrete optimization problems. Moreover, they are complex and are difficult to implement efficiently, and they may be susceptible to numerical noise.

Global optimization algorithms offer a much better chance of finding the global or near global optimum than the local algorithms (Mukherjee and Ray, 2006; Venter, 2010). Genetic algorithms and simulated annealing are two types of the best global search methods (Corana et al., 1987; Duch and Korczak, 1998; Goffe et al., 1994; Jiang, 2013; Sexton et al., 1999).

The training procedure of the ANNs is generally divided into two important steps: (1) initialization and (2) optimization. The initialization process might involve allocating initial random values to the network's weights. This process can be done by local and/or global optimization algorithms.

The local methods tend to become trapped in a local solution that may or may not be the global solution. If these initial weights reach a local grade, which is probable, the learning algorithm will likely become trapped in a local solution. Thus, these algorithms require a good starting point to be effective.

On the other hand, global search techniques (such as GA and SA) are more capable to obtain the optimal solution and also they offer a much better chance of finding the global or near global optimum than the local algorithms. But, doing a complete training process (both the initialization and optimization steps) might be more complicated by the use of global methods such as GA and SA. Therefore, a complete training scenario depends on both the initialization and optimization processes.

\subsection{Genetic Algorithm (GA)}

The GA is a global search technique that finds the global optimum point from a set of solutions. As the algorithm continuously samples the parameter space, the search is directed toward the area of the best solution so far. This algorithm has been shown to use extremely well in gaining global solutions for difficult non-linear functions (Sexton et al., 1998) and has been used to develop many applications (e.g. Chow et al., 2002; Hao et al., 2001; Ketabchi and Ataie-Ashtiani, 2015; 
Kuo and Lin, 2013; Lemonge and Barbosa, 2004). Basically, there are four steps, comprising 1. Creation of population, 2. Selection, 3. Crossover, and 4. Mutation, in a GA algorithm (see Deb et al. (2000, 2002) and Horn et al. (1994) for more details).

\subsection{Simulated Annealing}

The simulated annealing (SA) method is a meta-heuristic technique for solving complex optimisation problems and is based on the physical phenomenon of annealing (Schlünz and Van Vuuren, 2013). It was first proposed by Kirkpatrick et al. (1983) and many applications have been developed using SA (e.g. Kumral, 2013; Meiri and Zahavi, 2006; Saraiva et al., 2011; Zameer et al., 2014).

The SA algorithm is a randomised search procedure that starts from an initial solution to the problem. A control parameter is set to an initial 'temperature' value and is systematically decreased according to a cooling schedule (see Hamzadayi et al., 2013 for more details). Before starting the SA algorithm, it is necessary to choose starting values for the parameters, the cooling schedule and the stopping conditions (see Eglese (1990); Ingber (1993) and Alavi and Gandomi, (2011) for more details).

\subsection{Model Development using Simple ANN Method}

Two ANN models with a feed-forward artificial neural network and back-propagation learning algorithm were developed to predict groundwater inflow to the open pit mine and the hydraulic heads in the observation wells at different distance from the centre of the pit, respectively. The simple ANN models were trained by different algorithms (such as: Powell method, Levenberg-Marquardt method, etc.). The obtained results were then compared together and finally the methods with the best results were selected. In the present case, the best results were obtained by the conjugate gradient coupled with Powell-Beale restarts method (Powell, 1977). For this purpose, the Neural Network Toolbox of MATLAB software, R2013b was used. The input layer, output layer, optimal architecture and transfer functions for each layer of these models are similar to those of the ANN-GA and ANN-SA models, which are described in the following section.

\subsection{Model Development using the ANN-GA and ANN-SA Methods}

In this manuscript, it is tried to develop predictive models so that in addition to applying the fewer and simpler input parameters than the numerical models, they can predict the groundwater inflow and hydraulic head, more accurately. To enhance the efficiency of ANN model, the GA and SA methods were used for initialization phase of training procedure. After reaching good starting points, local optimization (learning) algorithms were used for the optimization phase of training procedure and consequently for the training scenario of the ANN.

The ANN-GA and ANN-SA models are developed by considering the following ratios as input parameters:

\footnotetext{
1. Depth of pit penetration in aquifer
} 
2. $\frac{\text { Bottom base pit radius }}{\text { Top base pit radius }}$

3. $\frac{1}{\text { Pit advance time }}$;

4. $\frac{\text { Hydraulic head in observation wells }}{\text { Distance of observation wells from the centre of pit }}$.

During the pit advance, based on the Section 2.1, the ratios (1) and (2) can vary between 0 and 1.

As it is shown in Fig. 1, two observation wells 1 and 2 are drilled at 1250 and $1750 \mathrm{~m}$ distance from the centre of the pit, respectively. Rate of groundwater inflow from the confined aquifer to the Goushfil open pit mine and also the hydraulic heads, at the two observation wells around the pit during its advance, over 30 weeks are measured. All of these data and only the first 27 of them were used to predict the hydraulic head and the groundwater inflow, respectively. Therefore, "inverse of pit advance time" can be defined as $1 / 1,1 / 2,1 / 3 \ldots 1 / 29$ and 1/30.

By dividing the hydraulic head in each well by the distance to the well from the centre of pit, the ratio (4) can be calculated. If the dewatering process from the pit sump during the pit advance is conducted consistently, ratio (4) can decrease with time.

Table 1 gives the correlation Matrix between the ratios (1)-(4) and rate of groundwater inflow to the pit, (5). During the pit advance, ratios (2)-(4) and item (5) decreased with time and ratio (1) increased with time. Therefore, ratios (2)-(4) are positive correlated with "groundwater inflow" and (1) is negatively correlated.

Table 1. Correlation Matrix between the arguments of the input and output layer of the presented networks.

\begin{tabular}{lccccc}
\hline \multicolumn{1}{c}{ Parameter } & $(1)$ & $(2)$ & $(3)$ & $(4)$ & $(5)$ \\
\hline$(1)$ & 1 & -0.61 & -0.55 & -0.14 & -0.11 \\
$(2)$ & - & 1 & 0.75 & 0.01 & 0.04 \\
$(3)$ & - & - & 1 & 0.30 & 0.21 \\
$(4)$ & - & - & - & 1 & 0.33 \\
$(5)$ & - & - & - & - & 1
\end{tabular}

Two models were constructed to predict the groundwater inflow. In these models, the initialization phase of training procedure was implemented by GA and SA methods. Besides, the optimization phase, and in other words the learning phase, of them were attempted using a number of different local optimization (learning) methods. Levenberg-Marquardt (Marquardt, 1963; Moré, 1978) method provided the best results. Number of the layers and nodes per layer as well as type of the transform functions in each layer were optimally obtained during a run scenario of the networks using a loop which frequently improved these variables so that the optimal value/kind of them were achieved. Finally, the optimal architecture (4-5-3-1) of the ANN-GA and ANN-SA networks was found capable to predict groundwater inflow to the mine and hydraulic heads in the mine vicinity. It has two middle layers which have 5 and 3 nodes, respectively. In this architecture, 
the transfer function between the inputs, first and second hidden layers are hyperbolic tangent. It is a linear type (purelin) between the second hidden layer and the output layer (Fig. 2). By switching the last argument of the input layer, (4), with the argument of the output layer of the two previous models, two other new models with similar architecture were prepared to predict the hydraulic head in observation wells 1 and 2 (Fig. 1) for the time period of the mining process. Finally, four models were designed for two purposes: two models were to predict the groundwater inflow and two other models were to predict the hydraulic head. The methodology was implemented in MATLAB.

Depth of pit penetration in aquifer Aquifer thickness

Bottom base pit radius

Top base pit radius

1

Input layer First hidden Second hidden Output layer

Pit advance time

Hydraulic head

Distance from the centre of pit

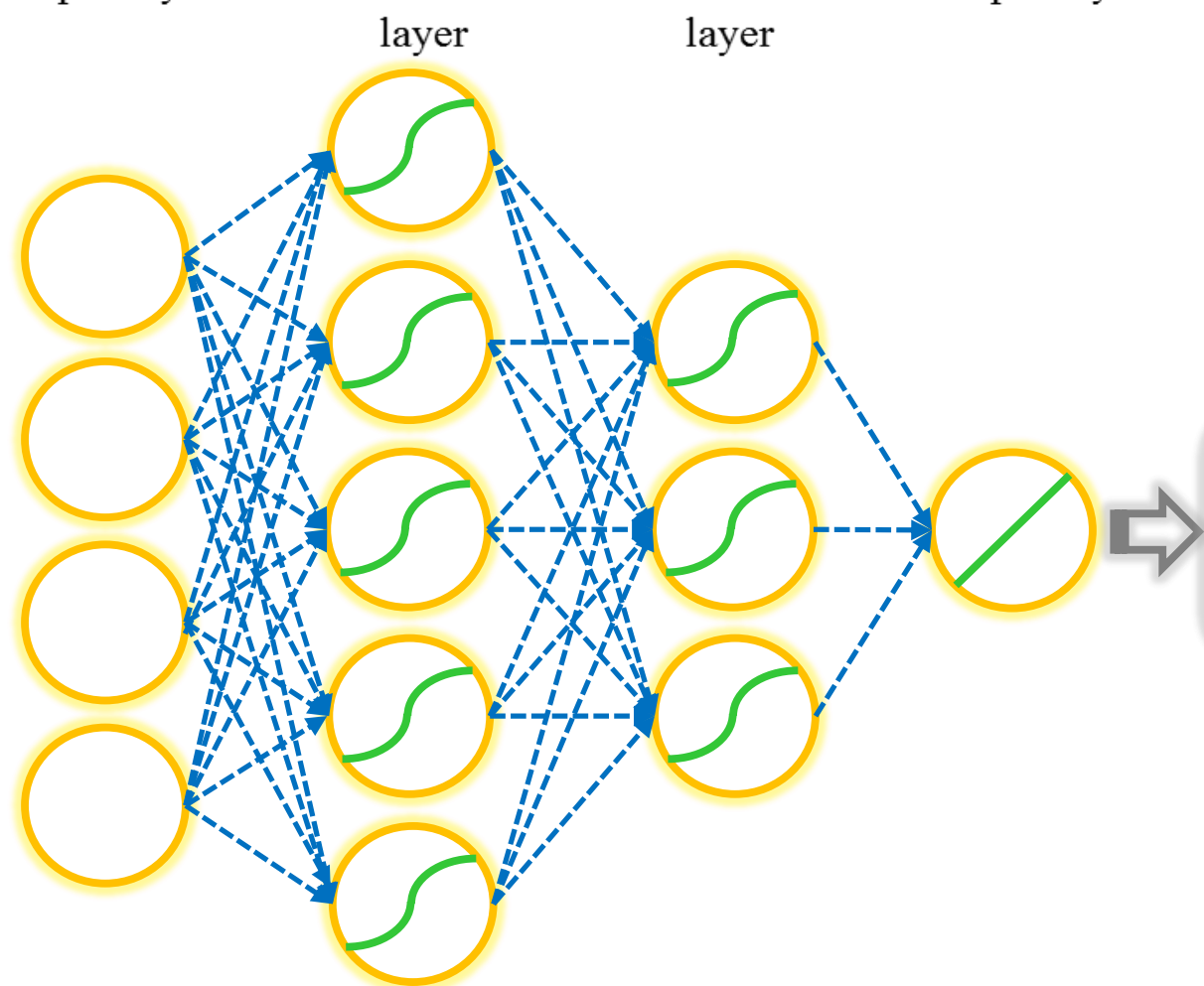

Groundwater inflow to mine pit

Fig. 2. ANN-GA and ANN-SA architecture with 4-5-3-1 arrangement with hyperbolic tangent and linear transfer functions. 


\subsection{Numerical Method}

\subsubsection{Simulation Tool and Governing Equation}

A commercial 2D finite element software called SEEP/W, developed by Geo-Slope International Ltd. (2012) was used to simulate groundwater inflow to an advancing open pit mine and the hydraulic heads in the observation wells. The software solves the governing flow Eq. 2 (Bahrami et al., 2014). The appropriate initial and boundary conditions must be specified to constrain the problem and make the solution unique.

$\frac{\partial}{\partial x}\left[k_{x}(\Psi) \frac{\partial \Psi}{\partial x}\right]+\frac{\partial}{\partial y}\left[k_{y}(\Psi) \frac{\partial \Psi}{\partial y}\right]+Q=C(\Psi)\left(\frac{\partial \Psi}{\partial t}\right)$

where, $k_{x}(\Psi)$ and $k_{y}(\Psi)$ are the permeability in $x$ and $y$ directions $(\mathrm{m} / \mathrm{s}) ; \Psi$ denotes matrix potential $(\mathrm{m}) ;(x, y)$ represent Cartesian coordinates (m); $t$ refers to time (s); $C(\Psi)$ stands for slope of the moisture characteristic curve $\left(\mathrm{m}^{-1}\right)$ and $Q$ is the boundary flux $\left(\mathrm{s}^{-1}\right)$.

Detailed theoretical aspects of SEEP/W software and the solution method for the governing equation are described elsewhere (e.g. Ardejani et al., 2003a, b; Gray and Pinder, 1974; Hofedank and Engineers, 1979).

\subsubsection{Conceptual Model}

A real geo-water system and its behaviour are often complicated and much detail is needed to describe such environments. One of the major steps in the modelling process is the construction of a conceptual model of the problem and of the relevant domain. The conceptual model includes a set of assumptions that reduce the real problem and the real domain to simplified versions that are satisfactory in view of the modelling objectives, the associated management problem, and the available data (Bear and Cheng, 2010).

Fig. 3 shows a conceptual model of the problem under investigation. This model identifies an open pit mine, a confined aquifer ruptured by the pit, initial hydraulic head, aquifer thickness and the pit depth at the aquifer. The flow vectors, aquifer boundaries and boundary conditions, drawdown curves, water level at the bottom of the pit, the pit advance and top and bottom base pit radiuses in each phase of pit advance are also illustrated.

Groundwater inflow to the pit takes place laterally from the pit walls and a vertical upward inflow occurs from the pit floor (Esfahan province environmental office, 2013). 


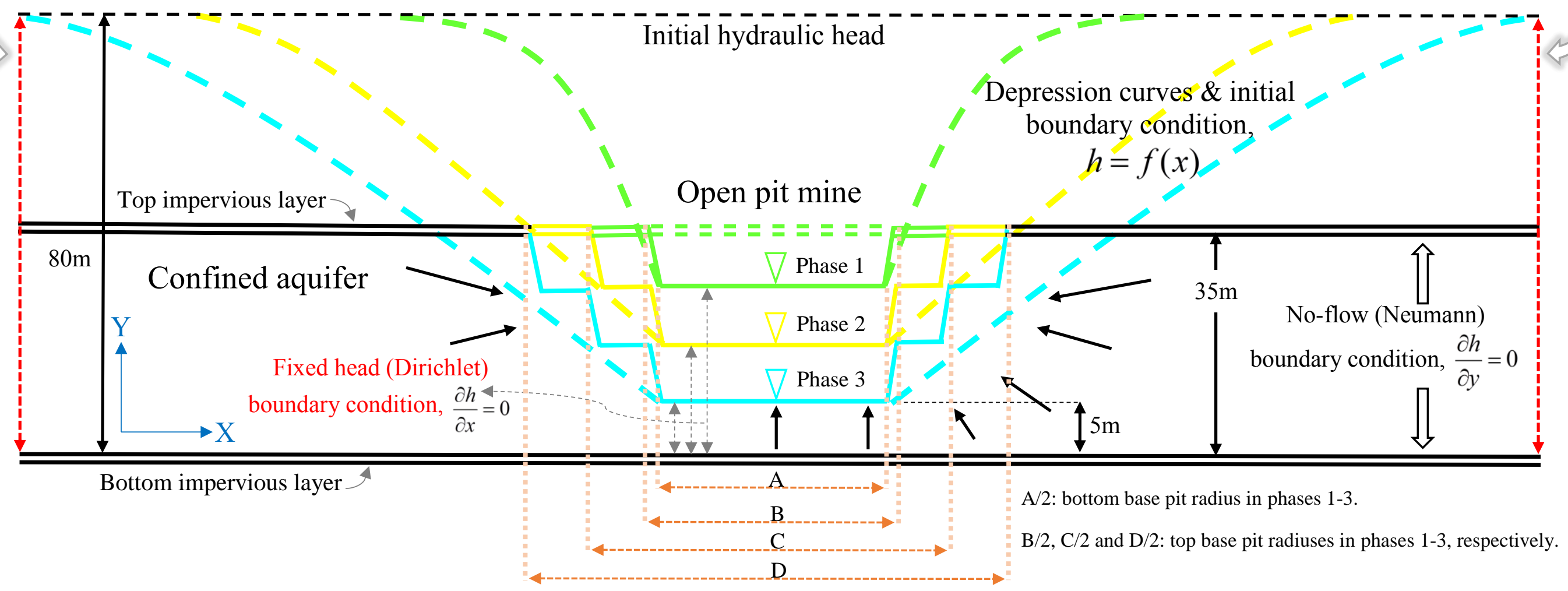

Fig. 3. Conceptual model of radial inflow from a confined aquifer to an advancing open pit mine.

\subsubsection{Evaluation of Aquifer Parameters}

The pump-out test data and values of hydraulic head monitored at an observation well, $15 \mathrm{~m}$ from the pumping well, were used to calculate the transmissivity and storage coefficient of the aquifer using the Cooper-Jacob equation (Cooper and Jacob, 1946; Kruseman and de Ridder, 1979) as follows:

$T=\frac{2.3 \times Q}{4 \pi \Delta S}$

where, $\mathrm{T}$ is the transmissivity $\left(\mathrm{m}^{2} / \mathrm{s}\right), \mathrm{Q}$ is the pumping rate $\left(8.5 \times 10^{-2} \mathrm{~m}^{3} / \mathrm{s}\right)$ and $\Delta S$ represents drawdown $(11.118 \mathrm{~m})$.

Thus, the average transmissivity of the aquifer is calculated equal to $0.0014 \mathrm{~m}^{2} / \mathrm{s}$.

The average hydraulic conductivity of the aquifer can be expressed as:

$K=\frac{T}{m}$

where $m$ is the permeable thickness of the aquifer $(35 \mathrm{~m})$ and $T$ represents transmissivity $\left(\mathrm{m}^{2} / \mathrm{s}\right)$.

Thus, the hydraulic conductivity $(K)$ will be $4 \times 10^{-5} \mathrm{~m} / \mathrm{s}$.

The storage coefficient (S) can be calculated using the following equation:

$S=\frac{2.25 \times T \times t_{0}}{r^{2}}$

where, $t_{0}$ is the intercept of drawdown line with the time axis $\left(t_{0}=6349.2 \mathrm{~s}\right)$ and $r$ denotes the radial distance from the pumping well $(15 \mathrm{~m})$. Thus, the storage coefficient of the aquifer will be 0.1 .

\subsubsection{Model Verification}

One real problem is described related to the pumping test in a confined aquifer to further verify the modelling results. A finite element grid incorporating 253 nodes and 50 elements in a single $35 \mathrm{~m}$ thick layer with a length of $40 \mathrm{~m}$ was built to model the pumping test in the confined aquifer. The rectangular mesh comprised eight-noded elements with an infinite 
element at the outer boundary of the aquifer in order to simulate an infinite, homogenous aquifer extending away from the pumping well. The grid spacing increases from the pumping well to the outer boundary with a size ratio of 3 . The size ratio is the ratio of the length of the last element to that of the first element along the side (Geo-slope International Limited, 2012). A steady-state simulation was first run to establish an initial condition. A total head of $80 \mathrm{~m}$ was assigned at the two sides of the aquifer. Hence, a uniform total head distribution of $80 \mathrm{~m}$ was generated throughout the entire aquifer. An axisymmetric simulation was run by considering a radial flow towards the pumping well. 15 time steps were considered to simulate transient flow conditions. The following boundary conditions were assigned to the transient model:

- No-flow condition at the upper and lower boundaries of the confined aquifer.

- A constant head boundary at the right-hand side of the model.

- A flux boundary at the left-hand side of the model next to the pumping well.

The input parameters to the inflow model were:

- Aquifer permeability $=4 \times 10^{-5} \mathrm{~m} / \mathrm{s}$,

- Storage coefficient $=0.1$,

- Initial hydraulic head $=80 \mathrm{~m}$,

- Thickness of the confined aquifer $=35 \mathrm{~m}$,

- Pumping out rate $=8.5 \times 10^{-2} \mathrm{~m}^{3} / \mathrm{s}$,

- The well radius $=0.25 \mathrm{~m}$.

Fig.4 compares the results of the numerical simulation and the field data for hydraulic head at an observation well, $15 \mathrm{~m}$ from the pump-out test well. The simulation results are in close agreement with the monitored field data, displaying a relative error of $0.05 \%$.

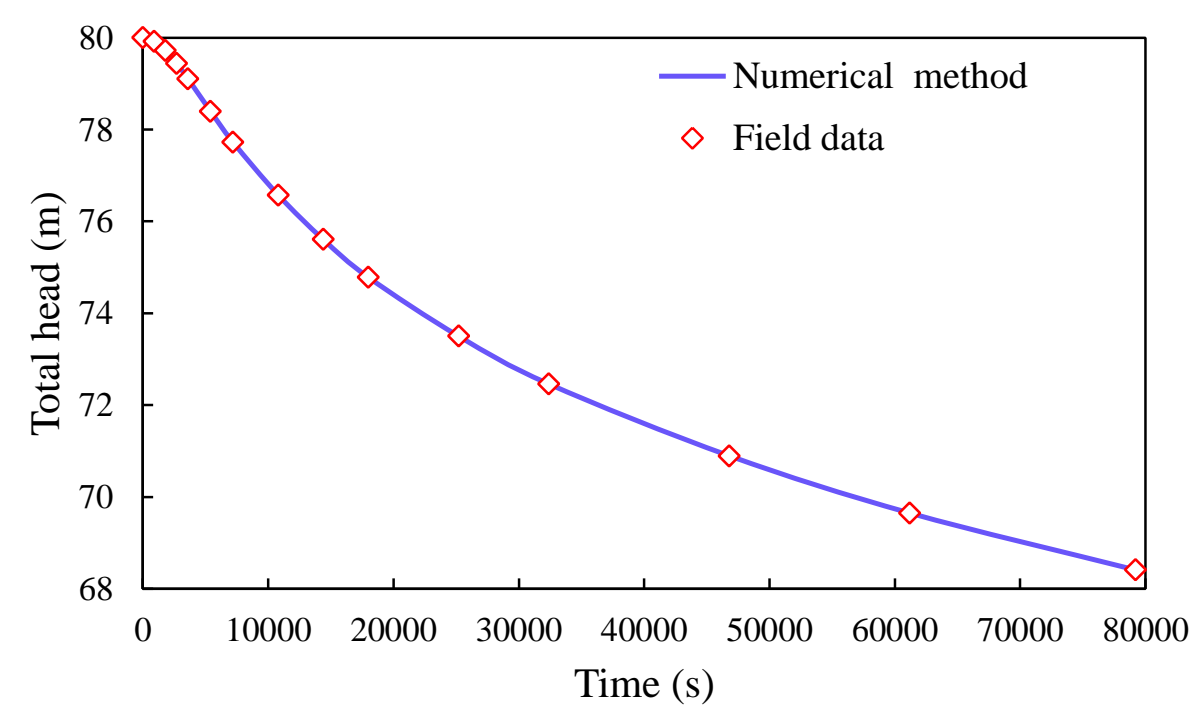

Fig. 4. Comparison of hydraulic head predicted by numerical model (solid line) and field data (diamonds) at an observation well, $15 \mathrm{~m}$ from the pumping test well. 


\subsubsection{Sensitivity Analysis}

A sensitivity analysis was carried out to gain insight into how the modelling results are affected by variability (or uncertainty) of the input variables of the numerical model. The main parameters considered were hydraulic conductivity, aquifer storage coefficient, initial hydraulic head and aquifer thickness. According to Fig. 5, it is evident that simulation results are very sensitive to the hydraulic conductivity and storage coefficient of the confined aquifer. 

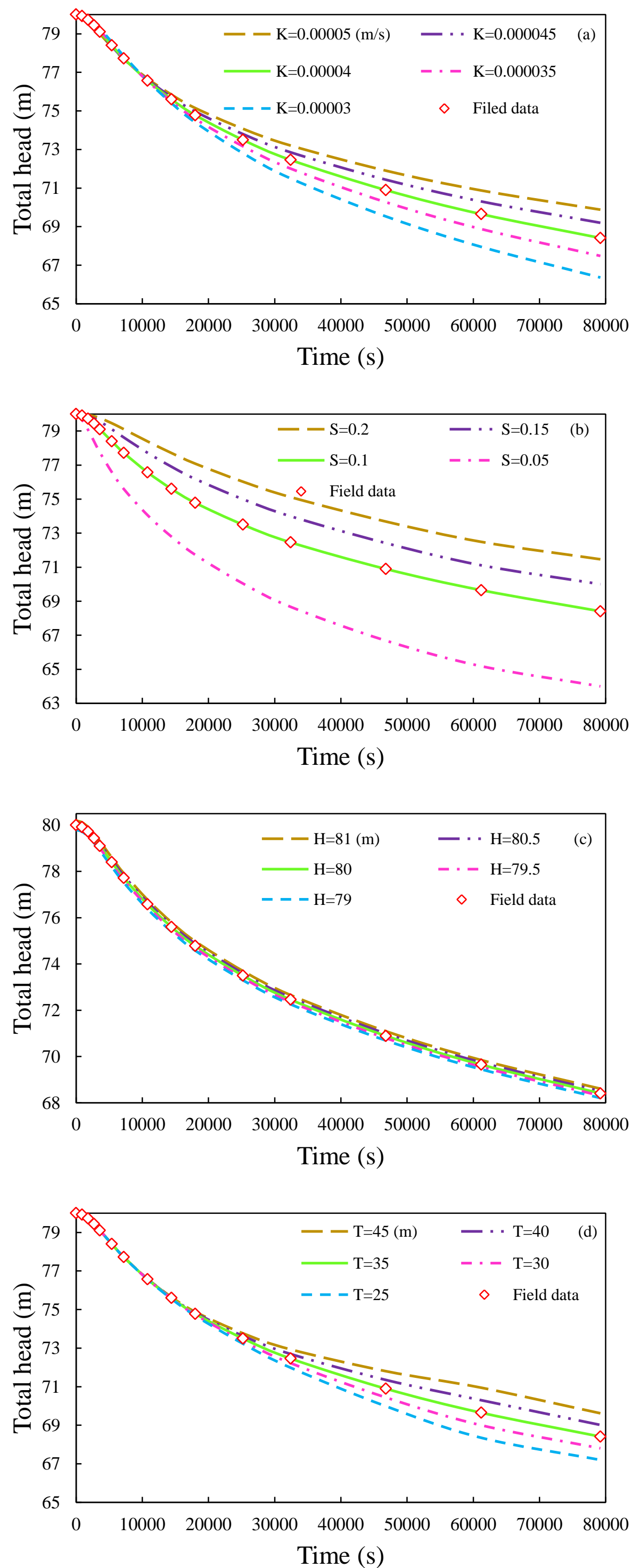

Fig. 5. Sensitivity of the model to: a. hydraulic conductivity, b. storage coefficient, c. initial head and d. aquifer thickness. 


\subsubsection{Numerical Model Development}

To model groundwater inflow during mine advance, three successive simulations were run (Fig. 6). A number of special boundary conditions and important input parameters used by all models incorporate:

- No-flow conditions at the upper and lower boundaries of the aquifer,

- An infinite element at the outer boundary, at the right-hand side of the confined aquifer,

- A constant head boundary at the right-hand side of the models $=80 \mathrm{~m}$,

- Hydraulic conductivity $=4 \times 10^{-5} \mathrm{~m} / \mathrm{s}$,

- Storage coefficient $=0.1$,

- Aquifer thickness $=35 \mathrm{~m}$,

- Model length $=2500 \mathrm{~m}$. 

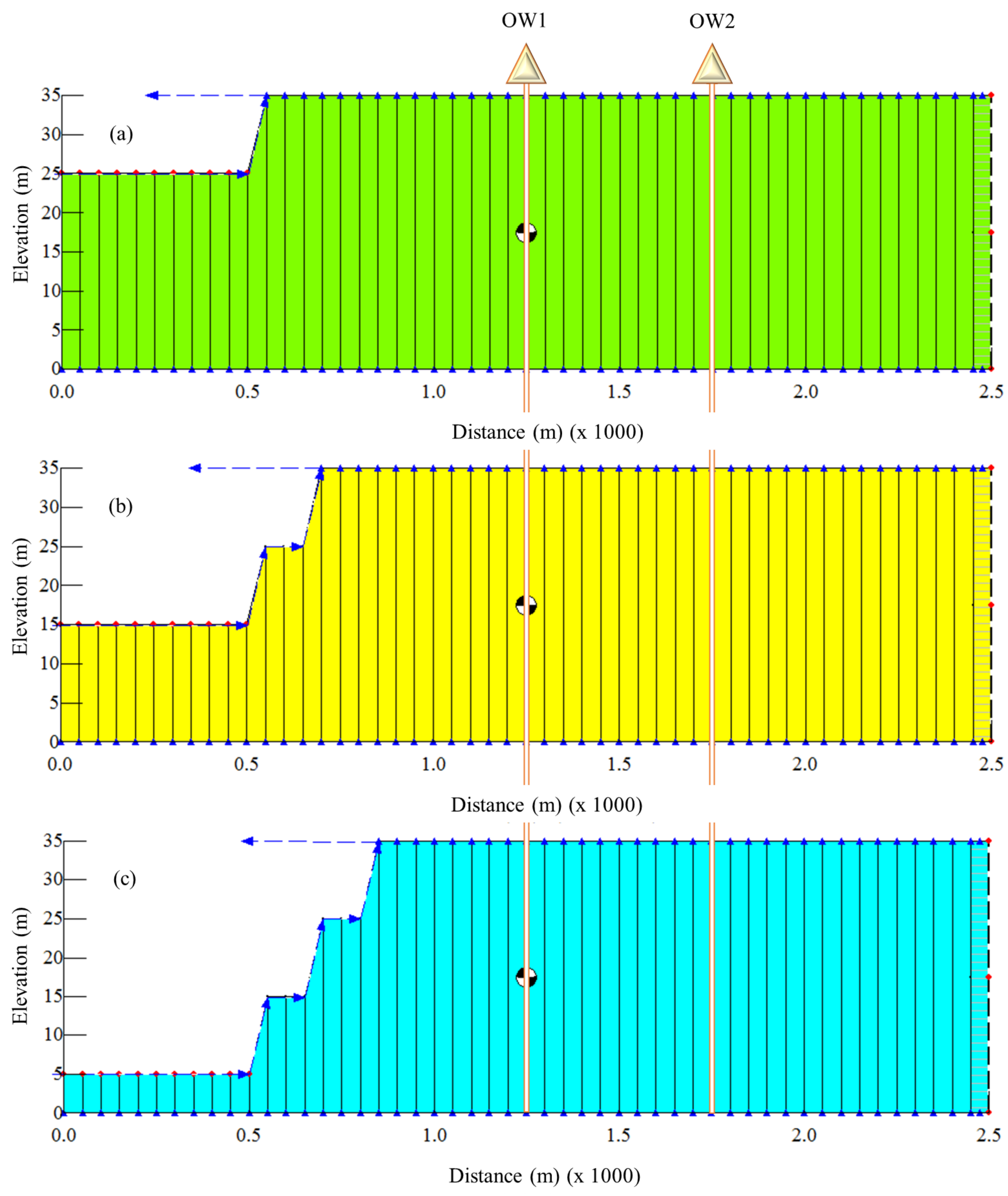

- Fig. 6. Finite element grids for modelling the groundwater inflow and hydraulic head during pit advance: a. phase 1, b. phase 2 and c. phase 3 and location of observation wells 1 and 2 . 
An axisymmetric finite element analysis was run using a grid with 50 elements and 102 nodes, the rectangular grid consisting of four-noded elements. Numbers of time steps were 8, 10 and 9 for phase 1 (weeks 1-8), phase 2 (weeks 8-18) and phase 3 (weeks 18-27), respectively. The axisymmetric analysis simulates a radial flow to the mine. The total simulation time was 27 weeks.

The advance of the pit was simulated by assigning a constant head at the radius of the pit corresponding to specified pit depths at various stages of the pit advance.

After constructing the finite element grid and applying the hydraulic conductivity, a steady-state simulation was carried out to build an initial condition for the aquifer before transient simulations were carried out. Constant heads of $80 \mathrm{~m}$ were allocated at the two ends of the aquifer and the modelling was then run. This simulation generated a uniform total head distribution of $80 \mathrm{~m}$ throughout the entire aquifer, representing the pre-mining situation. More details can be seen in Doulati Ardejani et al. (2003a).

In the first stage of the transient simulation with 8 time steps, a constant head of $25 \mathrm{~m}$ was specified at the mine excavation. By calling the initial condition and by specifying a storage coefficient of 0.1 , the inflow to the pit was predicted during each phase.

Similarly, by assigning appropriate constant heads of 15 and $5 \mathrm{~m}$ at the mine excavation, the second and the third phases respectively of transient simulations were carried out. The predictions obtained for the last time step of each phase of the simulation were used to provide the initial conditions for predicting inflows during the following phase of the simulation.

To predict hydraulic heads at the observation wells 1 and 2, the finite element mesh of each model (Fig. 6) was constructed so that the observation wells were exactly located on the nodes at different distances from the pit axis.

\subsection{Performance Measures}

The performance of the network presented is evaluated by using statistical parameters such as correlation coefficient (R), mean absolute error (MAE), mean absolute percentage error (MAPE) and mean squared error (MSE) values as follows (Alavi and Gandomi, 2011):

$$
\begin{aligned}
& R=\frac{\sum_{i=1}^{n}\left(h_{i}-\hbar\right)\left(t_{i}-t\right)}{\sqrt{\sum_{i=1}^{n}\left(h_{i}-\hbar\right)^{2} \sum_{i=1}^{n}\left(t_{i}-t\right)^{2}}} \\
& M A E=\frac{\sum_{i=1}^{n}\left|h_{i}-t_{i}\right|}{n} \\
& M A P E=\frac{1}{n} \sum_{i=1}^{n}\left[\left|\frac{h_{i}-t_{i}}{h_{i}}\right|\right] \\
& M S E=\frac{\sum_{i=1}^{n}\left(h_{i}-t_{i}\right)^{2}}{n}
\end{aligned}
$$

Where, $h_{i}$ and $t_{i}$ are the observation and predicted output values for the $i$ th output respectively, $\hbar$ and $€$ represent the average of the observation and predicted outputs, and n denotes the number of samples. 


\section{Results and Discussion}

\subsection{Results of Groundwater Inflow Prediction to the Mine}

According to Table 1, the absolute correlation values between output layer of the networks, ratio (5), and the parameters of the input layer vary between 0.04 and 0.33 . If they exceed 0.5 , the other simpler methods, such as a simple regression method could solve the problem and consequently it is not required to implement more complicated methods, such as ANNGA or ANN-SA methods. Hence, the use of the ANNs approach is justified. The top of Table 2 gives the R, MAE and MAPE values by ANN-GA, ANN-SA and simple ANN for the training and testing stages of groundwater inflow prediction. Based on this table, all of the ANNs models have the ability to be generalised. The 27 data sets were used for testing the networks. According to Table 2, only the ANN-GA and ANN-SA models have the capability to be good predictive tools. 
Table 2. Statistical parameters of ANN-GA, ANN-SA and simple ANN models for the training and testing stages of predicting the groundwater inflow and hydraulic head.

\begin{tabular}{|c|c|c|c|c|}
\hline Linear regression plot & Method & $\mathrm{R}$ & MAE & MAPE \\
\hline & ANN-GA & 0.99996 & 0.19 & 0.11 \\
\hline Field measured groundwater inflow against the predicted & ANN-SA & 0.9997 & 0.25 & 0.16 \\
\hline \multirow[t]{4}{*}{ inflow for the training stage } & Simple & & & \\
\hline & & 0.99758 & 0.29 & 0.199 \\
\hline & ANN & & & \\
\hline & ANN-GA & 0.99992 & 0.18 & 0.12 \\
\hline Field measured groundwater inflow against the predicted & ANN-SA & 0.99969 & 0.24 & 0.176 \\
\hline \multirow[t]{3}{*}{ inflow for the testing stage } & Simple & & & \\
\hline & ANN & 0.75095 & 1.07 & 0.55 \\
\hline & ANN-GA & 0.9999 & 0.15 & 0.017 \\
\hline Field measured hydraulic head $(\mathrm{HH})$ against the predicted & ANN-SA & 0.99995 & 0.199 & 0.145 \\
\hline \multirow[t]{3}{*}{$\mathrm{HH}$ for the training stage } & Simple & & & \\
\hline & ANN & 0.99906 & 0.21 & 0.185 \\
\hline & ANN-GA & 0.99996 & 0.172 & 0.103 \\
\hline Field measured hydraulic head $(\mathrm{HH})$ against the predicted & ANN-SA & 0.99987 & 0.197 & 0.15 \\
\hline \multirow[t]{3}{*}{$\mathrm{HH}$ for the testing stage (observation well 1) } & Simple & & & \\
\hline & ANN & $0.080 \angle 2$ & 0.32 & 0.21 \\
\hline & ANN-GA & 0.99984 & 0.101 & 0.065 \\
\hline Field measured hydraulic head $(\mathrm{HH})$ against the predicted & ANN-SA & 0.9973 & 0.144 & 0.138 \\
\hline \multirow[t]{2}{*}{$\mathrm{HH}$ for the testing stage (observation well 2) } & Simple & & & \\
\hline & ANN & 0.72975 & 0.49 & 0.341 \\
\hline
\end{tabular}

Fig. 7 compares the field measured inflow to the Goushfil pit with those inflows predicted by ANN-GA, ANN-SA, simple ANN, numerical model and analytical solutions (McWhorter, 1981; Singh et al., 1985) during the mine advance. The inflow quantities for three phases of pit advance decreased with time at different rates, so that phase 1 and phase 3 show the maximum and minimum decreasing rates respectively. Except for the beginning of the inflow prediction (between weeks 1 and 2), the analytical solutions underestimated the inflow quantities. The simple ANN model exhibits a decreasing trend of inflow with time, in general with frequent over- and underestimation. The ANN-GA method had a very good correlation with the field data. However, it slightly overestimated the inflow within week 9. 
In the first phase of transient prediction, the inflow decreased sharply from $4.84 \mathrm{~m}^{3} / \mathrm{s}$ to $0.95 \mathrm{~m}^{3} / \mathrm{s}$ within two weeks of the beginning of the pit advance. From week 2 to week 8 , it decreased linearly from $0.95 \mathrm{~m}^{3} / \mathrm{s}$ to $0.43 \mathrm{~m}^{3} / \mathrm{s}$. In these time steps, the ANN-SA method and numerical model slightly over- and underestimated the inflow, respectively. The inflow increased from $0.43 \mathrm{~m}^{3} / \mathrm{s}$ to $0.81 \mathrm{~m}^{3} / \mathrm{s}$ in the beginning of phase 2 (between weeks 8 and 9). It then decreased at almost same rate from $0.81 \mathrm{~m}^{3} / \mathrm{s}$ to $0.37 \mathrm{~m}^{3} / \mathrm{s}$ between times 9 and 10 weeks. Between weeks 10 and 18 , the inflow decreased steadily at a lower rate from $0.37 \mathrm{~m}^{3} / \mathrm{s}$ to $0.3 \mathrm{~m}^{3} / \mathrm{s}$ then, at times between 18 and 19 weeks, it increased from $0.3 \mathrm{~m}^{3} / \mathrm{s}$ to $0.37 \mathrm{~m}^{3} / \mathrm{s}$. It then decreased at almost same rate and reached $0.23 \mathrm{~m}^{3} / \mathrm{s}$ in week 20 . Both the ANN-SA method and numerical model overestimated the inflow during the second phase of prediction. As time progressed (from week 20 to week 27), the inflow decreased very slightly from $0.23 \mathrm{~m}^{3} / \mathrm{s}$ to $0.21 \mathrm{~m}^{3} / \mathrm{s}$ with a gradual rate of decline. In these time steps, ANN-SA slightly overestimated the inflow but the numerical method shows a good agreement with the field data.

According to Fig. 7, the inflow fluctuates at the beginning of each phase. The inflow fluctuation is relatively very large at phase 1. It, however, becomes smaller at the beginning of the subsequence phases due to reduction in water pressure of the confined aquifer and an increase in the available surface areas wherein inflow occurs.

Table 3 gives the mean percent error (MPE) in predicting groundwater inflow by ANN-GA, ANN-SA, simple ANN, numerical models and analytical solutions related to measured inflows over a 27-week time period. According to Tables 2 and 3 and Fig. 7, the ANN-GA, numerical and ANN-SA models showed a good fit with the field data.

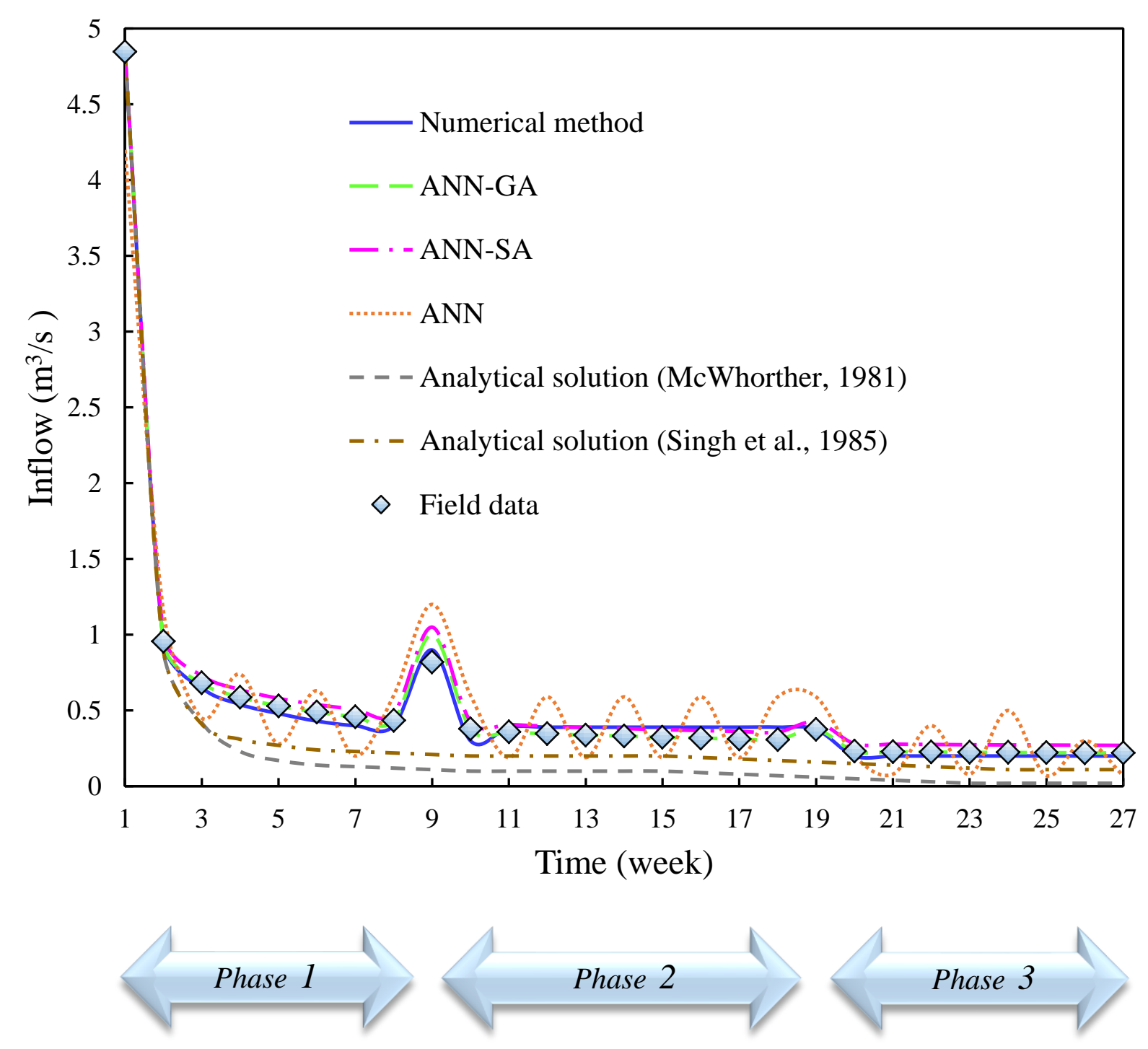

Fig. 7. Comparison of field data with those from ANN-GA, ANN-SA, simple ANN, numerical models and analytical solutions for groundwater inflow to Goushfil mine during pit advance. 
Table 3. Calculated errors of various models related to the field data for predicted groundwater inflow to the Goushfil open pit mine.

\begin{tabular}{|c|c|c|c|c|c|c|}
\hline \multirow[b]{2}{*}{ Model } & \multirow[b]{2}{*}{ ANN-GA } & \multirow[b]{2}{*}{ ANN-SA } & \multirow[b]{2}{*}{ ANNs } & \multirow{2}{*}{$\begin{array}{c}\text { Numerical } \\
\text { model }\end{array}$} & \multicolumn{2}{|c|}{ Analytical solution } \\
\hline & & & & & $\begin{array}{c}\text { Singh et al., } \\
1985\end{array}$ & $\begin{array}{c}\text { McWhorther, } \\
1981\end{array}$ \\
\hline MPE & 0.013 & 0.200 & 3.640 & 0.110 & 5.200 & 7.730 \\
\hline
\end{tabular}




\subsection{Results of Hydraulic head (HH) Prediction}

As Table 1 shows, the absolute correlation values between output layer of networks, ratio (4), and other parameters (input layer of networks) vary between 0.01 and 0.3 . The lower part of Table 2 shows the R, MAE and MAPE values by ANNGA, ANN-SA and simple ANN for the training and testing stages of predicting the HH. The performance results of the training stages indicate that all models have the ability to predict $\mathrm{HH}$. However, the performance results of the testing stages indicate that only the ANN-GA and the ANN-SA models show a close agreement with the field data. Figs. 8 and 9 compare the field data with those from ANN-GA, ANN-SA, simple ANN, and numerical models and analytical solutions (Kruseman and de Ridder, 1979; Theis, 1935) for HHs at observation wells 1 and 2, in the vicinity of the Goushfil pit, respectively. According to these figures, the $\mathrm{HH}$ decreases with time and also with a decrease in distance from the centre of the pit. The analytical solutions presented by Kruseman and de Ridder (1979) and Theis (1935) over- and underestimated the HHs respectively (at both of observation wells 1 and 2). Figs 8 and 9 also show that the simple ANN model indicates a decreasing trend of $\mathrm{HH}$ as a function of time with frequent over- and underestimation. ANN-SA slightly overestimated the HHs at two observation wells. The fluctuations in Figs. 8 and 9 are related to the progress of the pit phases. The reasons can be explained as the same manner as described in Section 4.1. Both the ANN-GA and numerical models results were a good fit with the field data, but the ANN-GA model results were the better of the two. Table 4 gives the mean percent error (MPE) in predicting the HH by the ANN-GA, ANN-SA, simple ANN, numerical model and analytical solutions, compared with the field data for the mining period. 


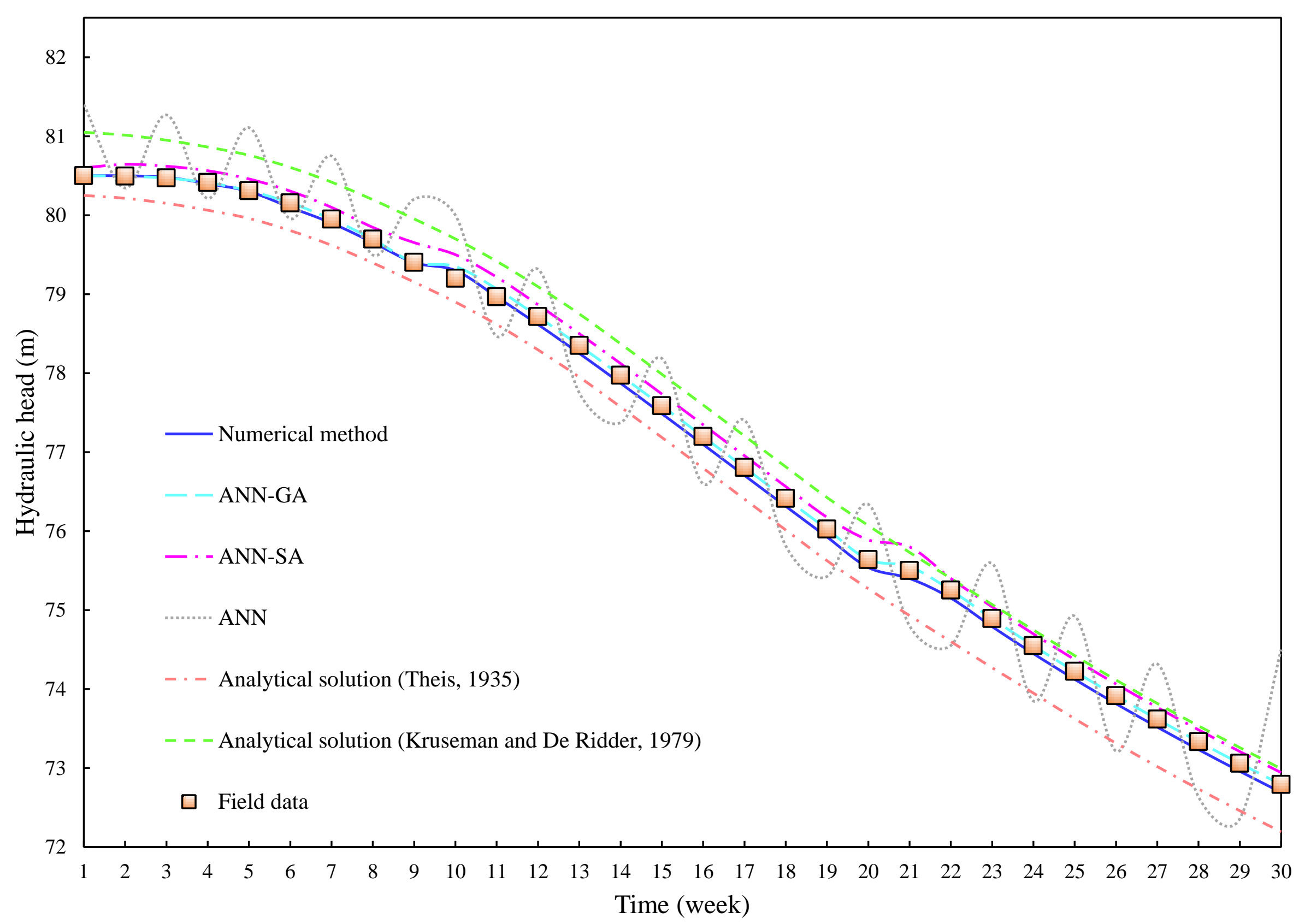

Fig. 8. Comparison of field measured HH with those predicted by ANN-GA, ANN-SA, simple ANN, and numerical models and analytical solutions at observation well 1 . 


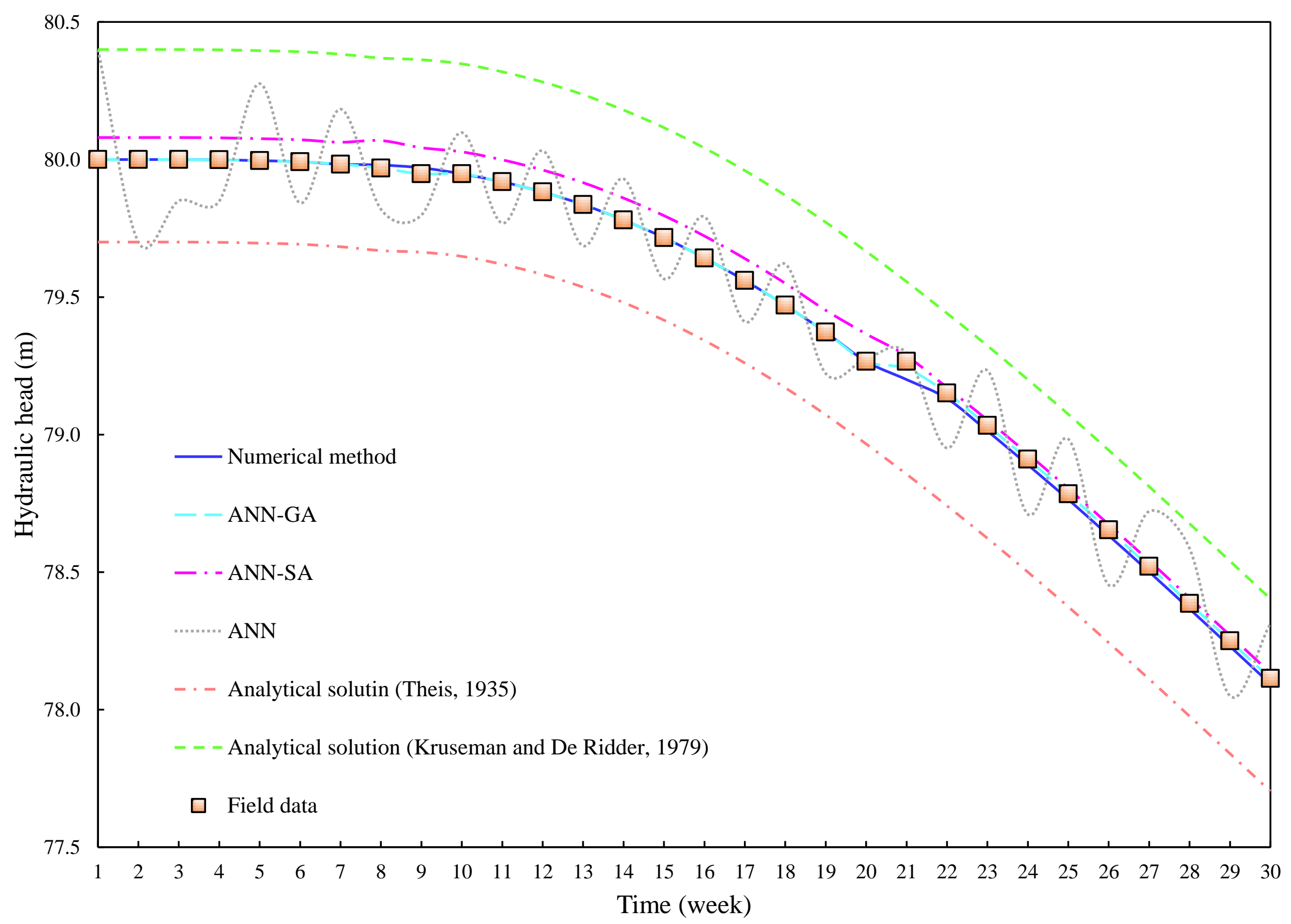

Fig. 9. Comparison of field data for HH with those predicted by ANN-GA, ANN-SA, simple ANN, and numerical models and analytical solutions at observation well 2 . 
Table 4. Calculated error related to the field data for predicted $\mathrm{HH}$ at observation wells 1 and 2.

Kruseman and

Model ANN-GA ANN-SA ANN Numerical Theis, $1935 \quad$ De Ridder,

1979

Observation

well 1

$<0.01$

0.38

3.64

0.20

5.20

6.70

Observation

$<0.01$

$<0.01$

0.51

5.10

0.33

8.47

9.50

well 2

\subsection{MSE Curves}

Figs. 10 and 11 show the networks' MSE as a function of time for the normalised output data. It can be observed from these figures that MSE for the ANN-GA and ANN-SA models during the initialization time step are markedly less than the ANN model which implies that they have very good initial values for the weights. Once the initialization phase is completed, the training process switches to the optimization phase. Since the networks reach an acceptable MSE quantity during the initialization phase, the optimization process attains a very low MSE value within the optimum time for each method.

It can be seen from Tables 2-4 that the ANN-GA and ANN-SA models with high R and low MAPE and MAE values provide acceptable estimates of the target values. The performance of the models on the training and testing data indicates that they have both good predictive ability and generalization performance. 


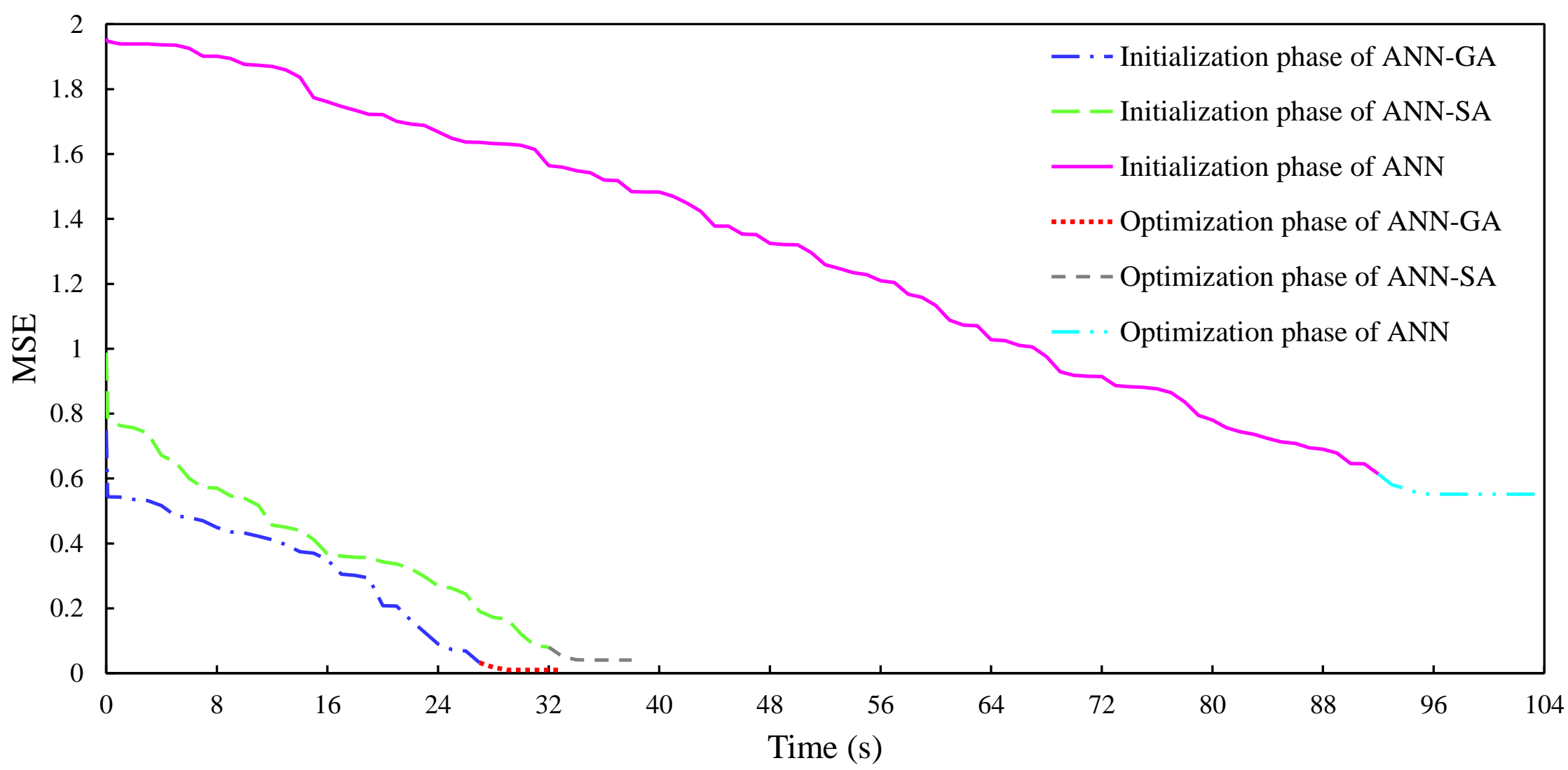

Fig. 10. Variations of the MSE values with time during the ANN-GA, ANN-SA and simple ANN training process for predicting groundwater inflow. 


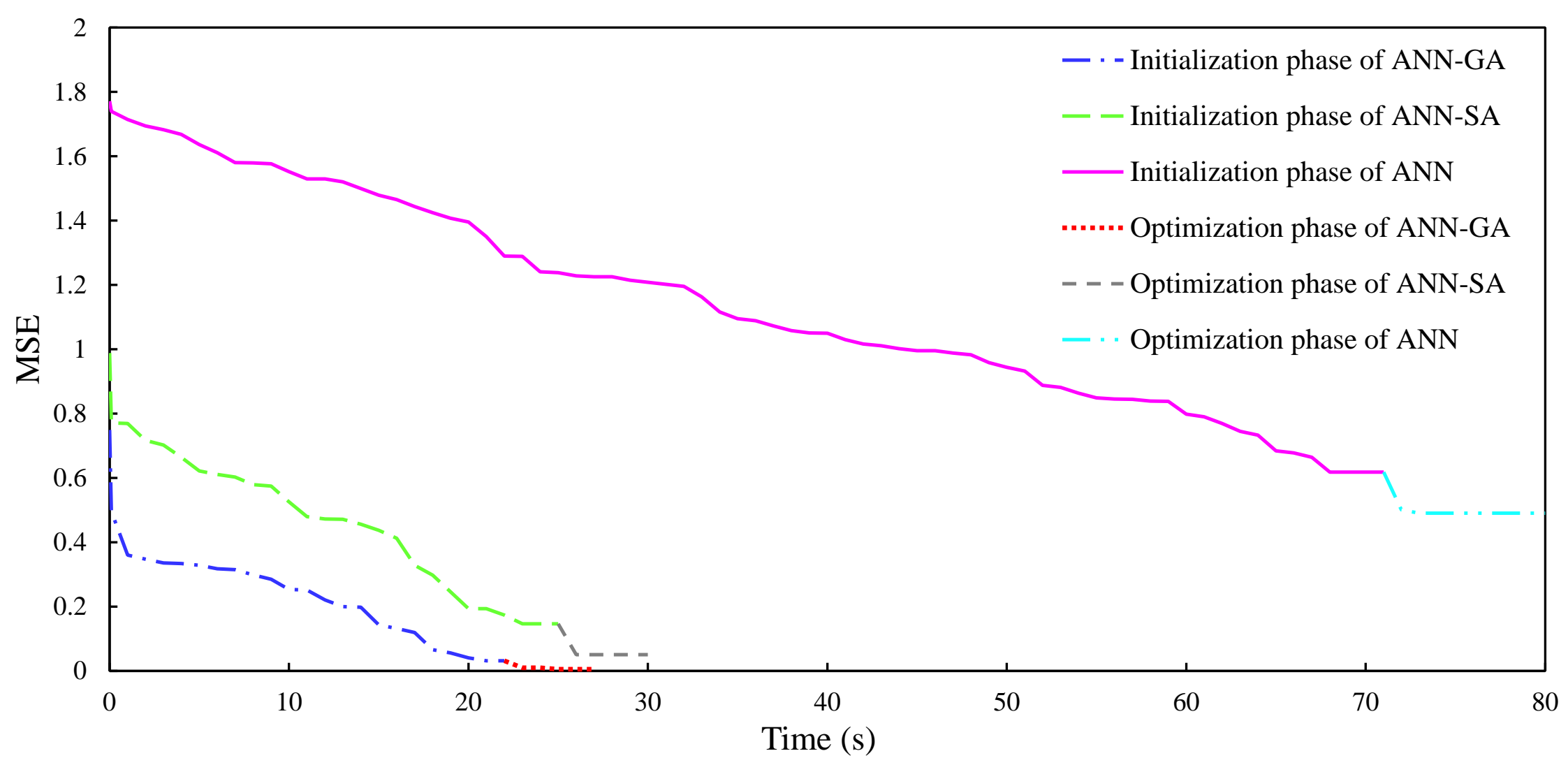

2 Fig. 11. Variations of the MSE values with time during the ANN-GA, ANN-SA and simple ANN training process for 3 predicting hydraulic head.

\section{5. Conclusions}

This paper presents a comprehensive comparison between the results of three different types of model (ANNs, numerical

model and analytical solutions) associated with two interesting and vital topics in mine hydrogeology. The main novelties of this research are as follows:

(1) The hybrid models proposed in the paper can be effectively used as appropriate tools that allow the mines holders to develop quickly and cost-effectively appropriate methods to control water problems at each stage of mine development.

(2) One of the great capabilities of the models presented here is their strong features and abilities to simulate non-linear water flow behaviour from complex geological strata towards a surface mine. However, analytical solutions are not as versatile as the hybrid models in dealing with complex hydrogeological-mining situations.

(3) As mine hydrogeologists are searching for appropriate models that have both the accuracy in prediction and the easy to use for implementation in solving the groundwater inflow problems, numerical models may be appropriate. However, in addition to the difficulties related to use of the numerical models, they need many input parameters and also, they impose much time and cost to the mine hydrogeologists.

On the other hand, the hybrid models utilise simpler and fewer inputs and can impose less time and cost to the mine owners. Furthermore, in comparison to the numerical and analytical solutions, they can accurately predict the mine inflow quantities when there is no sufficient time and hydrogeological data available to validate and justify the use of complex numerical models. 
It was found that analytical solutions both over- and underestimated the inflows and hydraulic heads. The simulated results of the numerical model used in this research are highly sensitive to the hydraulic conductivity and storage coefficient. In addition, the agreement between the predicted results and the field data was somewhat close.

Due to the difficulties related to the use of numerical models for hydrogeological modelling, we tried to develop predictive models so that in addition to applying the fewer and simpler input parameters than the numerical models, they can predict the groundwater inflow to open pit mine and hydraulic head at the vicinity of pit during the pit advance, more accurately. After running several simulation scenarios with a simple ANN model, an architecture of 4-5-3-1 was found as an optimal one to predict the groundwater inflow and hydraulic head. In this architecture, the transfer function between the inputs, first and second hidden layers were hyperbolic tangent. A linear transfer function (purelin) was adopted between the second hidden layer and the output layer.

The local optimization (learning) methods were used for the training procedure (both the initialization and optimization processes) of the simple ANN models. However, results show a similar trend change of inflow and hydraulic head as a function of time with frequent over- and underestimation.

Due to the fact that a comprehensive training scenario requires application of appropriate methods for initialization and optimization processes, we enhanced the efficiency of the simple ANN models. Therefore, they are modified so that the GA and SA methods were used for initialization phase of training procedure. After reaching good starting points, the Levenberg-Marquardt method was used for the optimization phase of training procedure and therefore for the learning process of ANNs.

The statistical parameters of the performance of models applying the training and testing data such as correlation coefficient (R), mean squared error (MSE), mean absolute error (MAE) and mean absolute percentage error (MAPE) indicate that the hybrid models have both good predictive ability and generalization performance.

The ANN-GA, ANN-SA and numerical models results all have a good fit with the field data, but the ANN-GA model shows the best correlation. Results further show that despite using the fewer and simpler (in terms of cost and time for data collection) parameters by the hybrid models, the ANN-GA and to some extent the ANN-SA have the ability to compete with the numerical models. The results of this paper can be used for planning, management and developing an effective dewatering program.

\section{Acknowledgements}

The authors thank the School of Mining, College of Engineering, University of Tehran for supporting this research. The technical support given by BAMA Company and Esfahan Province Environmental Office during the data acquisition process is acknowledged. Thanks are also due to the School of Civil, Mining and Environmental Engineering, University of Wollongong, Wollongong for providing SEEP/W software. 


\section{References}

Adamowski, J., Sun, K., 2010. Development of a coupled wavelet transform and neural network method for flow forecasting of non-perennial rivers in semi-arid watersheds. Journal of Hydrology, 390(1): 85-91.

Alavi, A.H., Gandomi, A.H., 2011. Prediction of principal ground-motion parameters using a hybrid method coupling artificial neural networks and simulated annealing. Computers \& Structures, 89(23): 2176-2194.

Doulati Ardejani, F., Singh, R., Baafi, E., Porter, I., 2003. A finite element model to: 2. Simulate groundwater rebound problems in backfilled open cut mines. Mine Water and the Environment, 22(1): 39-44.

Aryafar, A., Doulati Ardejani, F., Singh, R., 2009. Numerical modeling of groundwater inflow from a confined aquifer into Sangan open pit mine, northeast Iran. Geomechanics and Geoengineering: An International Journal, 4(3): 189-199.

Azrag, E.A., Ugorets, V.I., Atkinson, L.C., 1998. Use of a finite element code to model complex mine water problems, Proc. Int. Symp. on Mine Water and Environmental Impacts, Johannesburg, South Africa, pp. 31-41.

Bahrami, S., Doulati Ardejani, F., Aslani, S., Baafi, E., 2014. Numerical modelling of the groundwater inflow to an advancing open pit mine: Kolahdarvazeh pit, Central Iran. Environmental Monitoring and Assessment, 186(12): $8573-8585$.

BAMA Mining Company, 2003. Detailed exploration of Irankuh district.

Banerjee, P., Singh, V., Chatttopadhyay, K., Chandra, P., Singh, B., 2011. Artificial neural network model as a potential alternative for groundwater salinity forecasting. Journal of Hydrology, 398(3): 212-220.

Bear, J., Cheng, A.D., 2010. Modeling groundwater flow and contaminant transport, 23. Springer Science \& Business Media.

Belayneh, A., Adamowski, J., Khalil, B., Ozga-Zielinski, B., 2014. Long-term SPI drought forecasting in the Awash River Basin in Ethiopia using wavelet neural network and wavelet support vector regression models. Journal of Hydrology, 508: 418-429.

Bhattacharjya, R.K., Datta, B., 2009. ANN-GA-based model for multiple objective management of coastal aquifers. Journal of Water Resources Planning and Management, 135(5): 314-322.

Brawner, C., 1986. Groundwater and coal mining. Mining Science and Technology, 3(3): 187-198.

Cannas, B., Fanni, A., Tronci, S., Zedda, M., 2005. River flow forecasting using neural networks and wavelet analysis, Geophysical Research Abstracts, pp. 08651.

Chen, Y.H., Chang, F.J., 2009. Evolutionary artificial neural networks for hydrological systems forecasting. Journal of Hydrology, 367(1), 125-137.

Chiang, Y.-M., Chang, L.-C., Chang, F.-J., 2004. Comparison of static-feedforward and dynamic-feedback neural networks for rainfall-runoff modeling. Journal of hydrology, 290(3): 297-311. 
Chow, T., Zhang, G., Lin, Z., Song, C., 2002. Global optimization of absorption chiller system by genetic algorithm and neural network. Energy and Buildings, 34(1): 103-109.

Cooper, H.H., Jacob, C., 1946. A generalized graphical method for evaluating formation constants and summarizing wellfield history. Eos, Transactions American Geophysical Union, 27(4): 526-534.

Corana, A., Marchesi, M., Martini, C., Ridella, S., 1987. Minimizing multimodal functions of continuous variables with the "simulated annealing" algorithm Corrigenda for this article is available here. ACM Transactions on Mathematical Software (TOMS), 13(3): 262-280.

Crowe, A.S., Shikaze, S.G., Ptacek, C.J., 2004. Numerical modelling of groundwater flow and contaminant transport to Point Pelee marsh, Ontario, Canada. Hydrological Processes, 18(2): 293-314.

Davis, A., Zabolotney, G., 1996. Ground-water simulations for the determination of postmining recharge rates at the Belle Ayr Mine. Mining Engineering, 48(11): 80-85.

Deb, K., Agrawal, S., Pratap, A., Meyarivan, T., 2000. A fast elitist non-dominated sorting genetic algorithm for multiobjective optimization: NSGA-II. Lecture Notes in Computer Science, 1917: 849-858.

Deb, K., Pratap, A., Agarwal, S., Meyarivan, T., 2002. A fast and elitist multiobjective genetic algorithm: NSGA-II. Evolutionary Computation, IEEE Transactions on, 6(2): 182-197.

Dong, D., Sun, W., Xi, S., 2012. Optimization of mine drainage capacity using FEFLOW for the No. 14 Coal Seam of China's Linnancang Coal Mine. Mine Water and the Environment, 31(4): 353-360.

Doulati Ardejani, F., Sadeghiamirshahidi, M., Singh, R.N., Kish, T.E., Reed, S.M., 2013. Prediction of the groundwater rebound process in a backfilled open cut mine using an artificial neural network. Mine Water and the Environment, 32(4): 251-257.

Doulati Ardejani, F., Singh, R., Baafi, E., Porter, I., 2003. A finite element model to: 1. predict groundwater inflow to surface mining excavations. Mine Water and the Environment, 22(1): 31-38.

Duch, W., Korczak, J., 1998. Optimization and global minimization methods suitable for neural networks. Neural Computing Surveys, 2: 163-212.

Eglese, R., 1990. Simulated annealing: a tool for operational research. European Journal of Operational Research, 46(3): $271-281$.

Esfahan province environmental office, 2013. Unpublished groundwater data of the Esfahan province.

Fazeli, H., Soleimani, R., Ahmadi, M.-A., Badrnezhad, R., Mohammadi, A.H., 2013. Experimental study and modeling of ultrafiltration of refinery effluents using a hybrid intelligent approach. Energy \& Fuels, 27(6): 3523-3537.

Geo-slope International Limited. 2012. SEEPW Software Package for finite element seepage analysis, Available online at: http:www.geoslope.com/products/seepw.asp. 
Goffe, W.L., Ferrier, G.D., Rogers, J., 1994. Global optimization of statistical functions with simulated annealing. Journal of Econometrics, 60(1): 65-99.

Gray, W.G., Pinder, G.F., 1974. Galerkin approximation of the time derivative in the finite element analysis of groundwater flow. Water Resources Research, 10(4): 821-828.

Hamzadayi, A., Topaloglu, S., Kose, S.Y., 2013. Nested simulated annealing approach to periodic routing problem of a retail distribution system. Computers \& Operations Research, 40(12): 2893-2905.

Hanna, T., Azrag, E., Atkinson, L., 1994. Use of an analytical solution for preliminary estimates of ground water inflow to a pit. Mining Engineering, 46(2): 149-152.

Hao, Z., Kefa, C., Jianbo, M., 2001. Combining neural network and genetic algorithms to optimize low NO x pulverized coal combustion. Fuel, 80(15): 2163-2169.

Hao, Z., Qian, X., Cen, K., Jianren, F., 2004. Optimizing pulverized coal combustion performance based on ANN and GA. Fuel Processing Technology, 85(2): 113-124.

Hernández, J.-H., Padilla, F., Juncosa, R., Vellando, P.R., Fernández, Á., 2012. A numerical solution to integrated water flows: Application to the flooding of an open pit mine at the Barcés river catchment-La Coruña, Spain. Journal of Hydrology, 472: 328-339.

Hofedank, R.H., Engineers, O.G.C., 1979. Computation of and experience on lignite opencast mine drainage, Proceedings of the First International Mine Drainage Symposium. Denver, Colorado, pp. 383-408.

Horn, J., Nafpliotis, N., Goldberg, D.E., 1994. A niched Pareto genetic algorithm for multiobjective optimization, Evolutionary Computation, 1994. IEEE World Congress on Computational Intelligence., Proceedings of the First IEEE Conference on. Ieee, pp. 82-87.

Imrie, C., Durucan, S., Korre, A., 2000. River flow prediction using artificial neural networks: generalisation beyond the calibration range. Journal of Hydrology, 233(1): 138-153.

Ingber, L., 1993. Simulated annealing: Practice versus theory. Mathematical and Computer Modelling, 18(11): 29-57.

Jiang, J., 2013. BP neural network algorithm optimized by genetic algorithm and its simulation. International Journal of Computer Science Issues, 10(2): 516-520.

Kana, E.G., Oloke, J., Lateef, A., Adesiyan, M., 2012. Modeling and optimization of biogas production on saw dust and other co-substrates using Artificial Neural network and Genetic Algorithm. Renewable Energy, 46: 276-281.

Keqiang, H., Dong, G., Xianwei, W., 2006. Mechanism of the water invasion of Gaoyang Iron Mine, China and its impacts on the mine groundwater environment. Environmental Geology, 49(8): 1163-1172.

Ketabchi, H., Ataie-Ashtiani, B., 2015. Evolutionary algorithms for the optimal management of coastal groundwater: a comparative study toward future challenges. Journal of Hydrology, 520, 193-213.

Khalil, B., Ouarda, T., St-Hilaire, A., 2011. Estimation of water quality characteristics at ungauged sites using artificial neural networks and canonical correlation analysis. Journal of Hydrology, 405(3): 277-287. 
Kirkpatrick, S., Gelatt, C.D., Vecchi, M.P., 1983. Optimization by simulated annealing. science, 220(4598): 671-680.

Kruseman, G.P., de Ridder, N.A., 1979. Analysis and evaluation of pumping test data. International Institute for Land Reclamation and Improvement The Netherlands.

Kumral, M., 2013. Optimizing ore-waste discrimination and block sequencing through simulated annealing. Applied Soft Computing, 13(8): 3737-3744.

Kuo, H.-C., Lin, C.-H., 2013. A Directed Genetic Algorithm for global optimization. Applied Mathematics and Computation, 219(14): 7348-7364.

Lemonge, A.C., Barbosa, H.J., 2004. An adaptive penalty scheme for genetic algorithms in structural optimization. International Journal for Numerical Methods in Engineering, 59(5): 703-736.

Lewis, R., 1999. Predicting the steady-state water quality of pit lakes. Mining Engineering, 51(10): 54-58.

Marinelli, F., Niccoli, W.L., 2000. Simple analytical equations for estimating ground water inflow to a mine pit. Groundwater, 38(2): 311-314.

Marquardt, D.W., 1963. An algorithm for least-squares estimation of nonlinear parameters. Journal of the Society for Industrial \& Applied Mathematics, 11(2): 431-441.

McWhorter, D.B., 1981. Predicting groundwater response to disturbance by mining-selected problems, Symp. Surfzce Mining, Hydrology, Sedimentology and Reclamation, University of Kentucky, pp. 89-95.

Meiri, R., Zahavi, J., 2006. Using simulated annealing to optimize the feature selection problem in marketing applications. European Journal of Operational Research, 171(3): 842-858.

Mekanik, F., Imteaz, M., Gato-Trinidad, S., Elmahdi, A., 2013. Multiple regression and Artificial Neural Network for longterm rainfall forecasting using large scale climate modes. Journal of Hydrology, 503: 11-21.

Moré, J.J., 1978. The Levenberg-Marquardt algorithm: implementation and theory, Numerical analysis. Springer, pp. 105116.

Morton, K.L., Van Mekerk, F., 1993. A phased approach to mine dewatering. Mine Water and the Environment, 12(1): 2733.

Mukherjee, I., Ray, P.K., 2006. A review of optimization techniques in metal cutting processes. Computers \& Industrial Engineering, 50(1): 15-34.

Naugle, G., Atkinson, L., 1993. Estimating the rate of post-mining filling of pit lakes. MINING ENGINEERING-NEW YORK THEN LITTLETON COLORADO-, 45: 402-402.

Powell, M.J., 1977. Restart procedures for the conjugate gradient method. Mathematical Programming, 12(1): $241-254$.

Rabbani, M., Warner, J.W., 1994. Shortcomings of existing finite element formulations for subsurface water pollution modeling and its rectification: One-dimensional case. SIAM Journal on Applied Mathematics, 54(3): 660-673.

Reichert, J., 2007. A metallogenetic model for carbonate-hosted non-sulphide zinc deposits based on observations of Mehdi Abad and Irankuh, Central and Southwestern Iran. PhD thesis, Martin-Luther-Universität Halle-Wittenberg. 157 p. 
Rogowski, A., Weinrich, B., 1981. Modeling water flux on strip-mined land. Trans. ASAE;(United States), 24(4).

Sadeghiamirshahidi, M., Ardejani, F.D., 2013. Application of artificial neural networks to predict pyrite oxidation in a coal washing refuse pile. Fuel, 104: 163-169.

Saraiva, J.T., Pereira, M.L., Mendes, V.T., Sousa, J.C., 2011. A simulated annealing based approach to solve the generator maintenance scheduling problem. Electric Power Systems Research, 81(7): 1283-1291.

Schlünz, E., Van Vuuren, J., 2013. An investigation into the effectiveness of simulated annealing as a solution approach for the generator maintenance scheduling problem. International Journal of Electrical Power \& Energy Systems, 53: 166174.

Sexton, R.S., Dorsey, R.E., Johnson, J.D., 1998. Toward global optimization of neural networks: a comparison of the genetic algorithm and backpropagation. Decision Support Systems, 22(2): 171-185.

Sexton, R.S., Dorsey, R.E., Johnson, J.D., 1999. Beyond backpropagation: using simulated annealing for training neural networks. Journal of End User Computing, 11: 3-10.

Singh, R., Atkins, A., 1985a. Analytical techniques for the estimation of mine water inflow. International Journal of Mining Engineering, 3(1): 65-77.

Singh, R., Atkins, A., 1985b. Application of idealised analytical techniques for prediction of mine water inflow. Mining Science and Technology, 2(2): 131-138.

Singh, R., Atkins, A., Doulati Ardejani, F., 2012. Hydrogeological issues concerning the Thar Lignite prospect. Int. Journal of Mining \& Geo-Engineering, 46(2): 141-156.

Singh, R., Ngah, S., Atkins, A., 1985. Applicability of current groundwater theories for the prediction of water inflows to surface mining excavations, 2nd International Mine Water Congress of IMWA, Mine Water, Granada Spain, pp. 553569.

Singh, R., Reed, S., 1987. Estimation of pumping requirements for a surface mining operation, Proc. Symp. on Pumps and Pumping, Nottingham University, England, pp. 1-24.

Singh, R., Atkins, A., 1984. Application of analytical solutions to simulate some mine inflow problems in underground coal mining. International Journal of Mine Water, 3(4): 1-27.

Sivakumar, B., Jayawardena, A., Fernando, T., 2002. River flow forecasting: use of phase-space reconstruction and artificial neural networks approaches. Journal of Hydrology, 265(1): 225-245.

Sreekanth, J., Datta, B., 2015. Review: Simulation-optimization models for the management and monitoring of coastal aquifers. Hydrogeology Journal, 23(6): 1155-1166.

Theis, C.V., 1935. The relation between the lowering of the piezometric surface and the rate and duration of discharge of a well using ground water storage. US Department of the Interior, Geological Survey, Water Resources Division, Ground Water Branch Washington, DC. 
Vandersluis, G., Straskraba, V., Effner, S., 1995. Hydrogeological and geochemical aspects of lakes forming in abandoned open pit mines. Proc on Water Resources at Risk, American Institute of Hydrology: 162-177.

Venter, G., 2010. Review of optimization techniques. Encyclopedia of Aerospace Engineering.

Yao, H., Vuthaluru, H., Tade, M., Djukanovic, D., 2005. Artificial neural network-based prediction of hydrogen content of coal in power station boilers. Fuel, 84(12): 1535-1542.

Yeh, W.W-G., 2015. Review: Optimization methods for groundwater modeling and management. Hydrogeology Journal, 23(6): 1051-1065.

Yoon, H., Jun, S.-C., Hyun, Y., Bae, G.-O., Lee, K.-K., 2011. A comparative study of artificial neural networks and support vector machines for predicting groundwater levels in a coastal aquifer. Journal of Hydrology, 396(1): 128-138.

Zameer, A., Mirza, S.M., Mirza, N.M., 2014. Core loading pattern optimization of a typical two-loop 300MWe PWR using Simulated Annealing (SA), novel crossover Genetic Algorithms (GA) and hybrid GA (SA) schemes. Annals of Nuclear Energy, 65: 122-131.

Zanchettin, C., Ludermir, T.B., 2007. Global optimization methods for designing and training feedforward artificial neural networks. Dynamics of Continuous, Discrete and Impulsive System, 14: 328-337. 